\title{
Indigenous Cultural Translation
}

Indigenous Cultural Translation is about the process that made it possible to film the 2011 Taiwanese blockbuster Seediq Bale in Seediq, an endangered indigenous language. Seediq Bale celebrates the headhunters who rebelled against or collaborated with the Japanese colonizers at or around a hill station called Musha starting on October 27, 1930, while this book celebrates the grandchildren of headhunters, rebels, and collaborators who translated the Mandarin-language screenplay into Seediq in central Taiwan nearly eighty years later.

As a "thick description" of Seediq Bale, this book describes the translation process in detail, showing how the screenwriter included Mandarin translations of Seediq texts recorded during the Japanese era in his screenplay, and then how the Seediq translators backtranslated these texts into Seediq, changing them significantly. It argues that the translators made significant changes to these texts according to the consensus about traditional Seediq culture they have been building in modern Taiwan, and that this same consensus informs the interpretation of the Musha Incident and of Seediq culture that they articulated in their MandarinSeediq translation of the screenplay as a whole. The argument more generally is that in building cultural consensus, indigenous peoples like the Seediq are "translating" their traditions into alternative modernities in settler states around the world.

Darryl Sterk is an Assistant Professor of Translation at Lingnan University in Hong Kong. He also translates literature, especially fiction from Taiwan. 


\section{Routledge Advances in Translation and Interpreting Studies}

\section{Humour in Audiovisual Translation}

Theories and Applications

Margherita Dore

\section{Evaluating the Evaluator}

A Novel Perspective on Translation Quality Assessment

Hansjörg Bittner

New Empirical Perspectives on Translation and Interpreting

Edited by Lore Vandevoorde, Joke Daems and Bart Defrancq

\section{Sense in Translation}

Essays on the Bilingual Body

Caroline Rabourdin

\section{Translation as Actor-Networking}

Actors, Agencies, and Networks in the Making of Arthur Waley's English

Translation of the Chinese 'Journey to the West'

Wenyan Luo

Chinese-English Interpreting and Intercultural Communication Jim Hlavac and Zhichang Xu

\section{Translation and Hegel's Philosophy}

A Transformative, Socio-narrative Approach to A.V. Miller's Cold-War

Retranslations

David Charlston

\section{Indigenous Cultural Translation}

A Thick Description of Seediq Bale

Darryl Sterk

For more information about this series, please visit www.routledge.com/RoutledgeAdvances-in-Translation-and-Interpreting-Studies/book-series/RTS 


\title{
Indigenous Cultural Translation
}

A Thick Description of Seediq Bale

\section{Darryl Sterk}

\author{
Routledge \\ Taylor \& Francis Group


First published 2020

by Routledge

2 Park Square, Milton Park, Abingdon, Oxon OX14 4RN

and by Routledge

52 Vanderbilt Avenue, New York, NY 10017

Routledge is an imprint of the Taylor \& Francis Group, an informa business

(C) 2020 Darryl Sterk

The right of Darryl Sterk to be identified as author of this work has been asserted by him in accordance with sections 77 and 78 of the Copyright, Designs and Patents Act 1988.

All rights reserved. No part of this book may be reprinted or reproduced or utilised in any form or by any electronic, mechanical, or other means, now known or hereafter invented, including photocopying and recording, or in any information storage or retrieval system, without permission in writing from the publishers.

Trademark notice: Product or corporate names may be trademarks or registered trademarks, and are used only for identification and explanation without intent to infringe.

British Library Cataloguing-in-Publication Data

A catalogue record for this book is available from the British Library

Library of Congress Cataloging-in-Publication Data

Names: Sterk, Darryl, author.

Title: Indigenous cultural translation : a thick description of Seediq Bale / Darryl Sterk.

Description: First. | New York : Routledge, 2020. | Includes bibliographical references and index.

Identifiers: LCCN 2019058261 (print) | LCCN 2019058262 (ebook) | ISBN 9780367198558 (hardback) | ISBN 9780429243738 (ebook)

Subjects: LCSH: Motion pictures_-Translating_-Taiwan. | Translating and interpreting - Taiwan. | Linguistic minorities-Taiwan. | Language and culture-Taiwan. | Truku (Taiwan people) - Language. | Motion pictures - Translations into Chinese. | Seediq language. | Warriors of the Rainbow: Seediq Bale.

Classification: LCC PN1995.9.T685 S74 2020 (print)

LCC PN1995.9.T685 (ebook) | DDC 777/.55-dc23

LC record available at https://lccn.loc.gov/2019058261

LC ebook record available at https://lccn.loc.gov/2019058262

ISBN: 978-0-367-19855-8 (hbk)

ISBN: 978-0-429-24373-8 (ebk)

Typeset in Times New Roman by Apex CoVantage, LLC

Visit the eResources: www.routledge.com/9780367198558 
This book is dedicated to the Seediq translators of Seediq Bale:

Watan Diro, Iwan Nawi, Pawan Nawi, Dakis Pawan, Iwan Pering, and Pawan Tanah.

Mhuwe namu bale! Mhuway namu balay! 
$\Longrightarrow$ Taylor \& Francis Taylor \& Francis Group http://taylorandfrancis.com 


\section{Contents}

List of tables viii

Preface

Acknowledgments xiii

Phonology xvi

Morphology xviii

Syntax $\quad \mathrm{xx}$

Introduction:

Indigenous modernity and the translation of Seediq Bale 1

1 From resistance to compromise:

Critical women in the Mandarin version 22

2 Refining the ore:

From foreignization and domestication to fluency 44

3 The game of telephone:

$\begin{array}{ll}\text { Cultural translation as adaptation } & 62\end{array}$

4 Pacifying the pine:

How to demilitarize headhunting songs $\quad 80$

5 The dialectic of dmahun:

The thicker backtranslation of cultural keywords 103

6 From Hako Utux to Rainbow Bridge:

Into the translational middle ground 130

7 Translating colonial modernity:

Adapting terminologically

Conclusion:

The thick description of indigenous cultural translation 


\section{List of tables}

\section{Front matter}

0.1 Seediq Pronouns xviii

0.2 Tense-Aspect-Modality and Focus Affixes on Seediq Verbs xix

\section{Introduction}

I.1 Timeline of Translation in the Textual History of the Screenplay of Seediq Bale

I.2 Plan of the Core Chapters

\section{Chapter 1}

1.1 Timeline of the Musha Incident in The Sun Flag and The Rainbow Bridge

\section{Chapter 2}

2.1 Phonological Comparison of English, Japanese, Mandarin, and Seediq

2.2 Syntactic Comparison of English, Japanese, Mandarin, and Seediq

\section{Chapter 6}

6.1 Seediq Dramatis Personae in Seediq Bale

6.2 Tgdaya and Toda Village Names

\section{Chapter 7}




\section{Preface}

This book is a thick description of a case of indigenous cultural translation.

The case is the screenplay of the Taiwanese blockbuster film Seediq Bale (directed by Wei Te-sheng, 2011), which was translated from Mandarin into Seediq, the endangered indigenous language in which most of the dialogue in the film is delivered. Compared with other films that contain dialogue in endangered indigenous languages, there is a lot in Seediq Bale. There is more dialogue in Seediq in Seediq Bale than there is in Inuktitut in Atanarjuat: The Fast Runner (directed by Zacharias Kunuk, 2001), and far more than there is in Lakota Sioux in Dances With Wolves (directed by Kevin Costner, 1990). The quantity of dialogue is not in itself a reason to study it. The reason I am studying it is for what it tells us about the team of Seediq translators who translated it, particularly how they see themselves as citizens of a modern state and inheritors of an indigenous tradition. I will discuss how the translation of the screenplay sheds light on how the translators see themselves in the introduction. In this preface I would like to clarify what I mean by thick description in my subtitle and by indigenous cultural translation, the title of this book.

"Thick description" is a phrase that the anthropologist Clifford Geertz borrowed from the philosopher of language Gilbert Ryle and applied to ethnography. Ryle's point was that description is interpretation. A description of a wink, for instance, is an interpretation of an observation of a flap of an eyelid. To call an eyelid flap a "wink" as opposed to a "blink," you have to assume the wink was intentional, that it was communicative (Geertz 1973: 6-7). In other words, you have to try to get inside the winker's head. A description in ethnography is thick in its reference to intersubjective "depths," and indeed thick description is sometimes translated "deep description" (深描 shēnmiáo) in Mandarin. This psychological understanding of thick description applies in this monograph in that I will be trying to get inside the translators' heads, to infer what they were thinking from their translation.

Geertz went beyond what his native informants were thinking. Thick description is also a process of layering the ethnographer's second-order interpretation upon the native informant's first-order interpretation (15), where in any case an interpretation can be conceived of as a description of the way in which something can be meaningful. The Seediq translators I have studied are quite capable of being self-reflexive or "meta," of explaining why they translated something in a 


\section{x Preface}

certain way; but if my own explanation is piggy-backed upon theirs, then it will be one order higher, and that much thicker.

But the thickness I am concerned with in this monograph is primarily of the "webs ${ }^{1}$ of significance" in which, Geertz claims, people search for meaning (5). The webs of significance are semiotic systems. In layperson's terms, they are cultures. How would such cultural webs be thick? It seems to me that they are thick in the way that hair is thick. The connections between key cultural concepts might be thick, and the web around any key concept is going be particularly thick, in that key concepts are densely or tightly interconnected nodes. I will be limning the lineaments of the web of Seediq culture in which the indigenous translators who made it possible to shoot Seediq Bale in Seediq make meaning of the texts they translate and of their lives. If you consider that they have spent their lives trying to understand the traditional lives that their mostly monolingual ancestors led until just over a century ago, but that they are themselves modern and bilingual, you can imagine that their cultural webs might get extremely thick. I can only hope they stay that way.

Thick description has been applied to translation by another philosopher of language, Anthony Kwame Appiah (2012 [1993]). For Appiah, a thick translation is one "that seeks with its annotations and its accompanying glosses to locate the text in a rich cultural and linguistic context" (341) so that a reader of the text in translation can get a sense of its use in "communicative actions" $(332,341)$ in the original culture. I share Appiah's ideal of thickness and have tried to live up to it in my own literary translation and in my description of Seediq translation. But I find Appiah's own thick translations of proverbs from the Ghanaian language Twi to be disappointingly thin, particularly regarding the "linguistic context." Though Appiah spells the proverbs out and provides what he calls "a literal translation" (331), he does not explain how the Twi words in each proverb combine into the meaningful utterance.

One way Appiah could have thickened his description is to sandwich a line of analysis between his romanization and his literal translation by adopting what Kate Sturge calls the "threefold or inter-linear translation method" (2007: 26) and which I will call a three-line presentation. Picture three lines. In the top line, an excerpt from an original is written out, usually in the roman alphabet. In the middle line, the "interlinear" line, the words in the top line are glossed, in order, word by word. As meaning is contextual, the glosses are approximations of the meanings of the words in the context of the top line. If the interlinear line contains morphological or syntactical "analysis," it can be challenging for a non-linguist to read. The bottom line is a translation, usually literal, of the entire line.

A three-line presentation is inadequate in itself. It has to be followed with the "pragmatic" commentary of the sort that Appiah provides (though he could have provided a lot more), so that the reader can understand how people in that culture do things with the words in the utterance, or with the non-verbal gesture to which the utterance might refer. A linguist friend of mine has observed indigenous people in Taiwan and the Philippines using their lips to do the communicative work we do with our eyes when we wink. But the commentary should also address the 
degree to which the glosses approximate the original words, which constrains how literal the translation in the bottom line can be. A language may not, for instance, have an exact analogue to "wink." In Seediq, tmuwak doriq means to "blink/wink the eyes."

Although a three-line presentation is a not a sufficient condition for thick translation, it is a necessary one. Without the middle line of analysis, the romanization in the top line is just clusters of letters. Without the line of analysis, the reader has no way of knowing how the words in the original have been "domesticated," meaning translated into words the reader is familiar with. In a truly thick translation, the words should be "foreignized," meaning translated in such a way that the reader can get a bit closer to them and to the web of culture in which they are meaningful nodes.

You will find an example of a three-line presentation at the beginning of the acknowledgments below in which, as you will see, a word meaning roughly "deed" stems from a root that can mean "cross," because the ultimate achievement in traditional Seediq culture was crossing a "rainbow bridge" into the afterlife. For the Seediq romanization, check the following section on phonology. For the abbreviations in the interlinear line of analysis, see the sections on morphology and syntax. I hope you will consult these sections as you read. If I get even one reader interested in Seediq or passionate about learning some other indigenous language, perhaps another Austronesian one, I will have achieved one of the goals of this book.

Needless to say, this book is not a linguistic study, nor did the interests that motivated it come out of linguistic theory. I imagine I share interests with scholars in linguistics, history, anthropology, Sinology, Taiwan studies, media studies, and indigenous studies, but I am a translator, and translation studies is the discipline in which this monograph has taken shape. I share more interests with scholars in different subfields in translation studies. I share an interest with scholars in audiovisual translation studies in how translation operates in an audiovisual context. ${ }^{2}$ I also share an interest with scholars in cultural translation studies in how translation might be transformative.

My debt to cultural translation studies, and to Clifford Geertz, should be evident in my approach, "indigenous cultural translation." I mean "translation" in three ways: interlingual translation, interpretation, and transformation. In translating a text interlingually, an indigenous translator interprets it in the web of his or her culture, and by the very act of interpretation, an indigenous translator is transforming the web and him- or herself.

My argument about indigenous cultural translation is a qualified endorsement of an assumption in minority translation studies that minority translators would, by virtue of their strong identities, tend to foreignize into the majority language to represent their cultural identity and domesticate into the minority language to preserve it. The Seediq translators I study in this book certainly have strong identities, which we can understand in the context of the local indigenous movement. Though none of them are radicals, the translators have all played parts in the indigenous struggle for rights and recognition in Taiwan. Evidently their indigenous 
identities have gotten stronger, because they are now much more likely to foreignize Seediq cultural terms into Mandarin than they were a few decades ago.

But the assumption that minority translators, including indigenous translators, would or should domesticate into their languages to preserve their cultural identities needs qualification. Had they simply domesticated, the Seediq translators would have replicated linguistic and cultural patterns, not innovated new ones. Indigenous translators should embrace, and scholars should endorse, foreignization because it is a driver of innovation and because it is not a threat: language vulnerability is not a linguistic problem, it is a sociolinguistic problem. Rather than worry about the effect foreignization might have on a vulnerable language, we as scholars should be describing translations and the transformations they engender as thickly as we can. That is what I have tried to do in this book.

What I found is that the Seediq translators foreignized and domesticated their ways to "fluencies" that constituted compromises with the original text, where their translation was both a transmission of the meaning of the original and an articulation of their own perspectives. Such translational compromises are part of an evolving Seediq compromise with Taiwan-style modernity. The translators have demonstrated their strength of identity not by preserving their culture but by translating it, meaning transforming or, better yet, "adapting" it.

Although I imagine my approach applies beyond Seediq Bale, I have written the book as a case study. The introduction has implications for the conditions of indigenous cultural translation from the early 20th century on, but it is an introduction to the case. In chapters 2 and 7, I relate my case study to minority translation studies scholarship. For the most part, however, I will wait until the conclusion before making a home for indigenous cultural translation in translation studies and suggesting how the thick description of cases of indigenous translation might shed light on the fates of indigenous ways of knowing and living around the world. 


\section{Acknowledgments}

In his reunion with his sister Mahung Mona at the end of The Rainbow Bridge, the second half of Seediq Bale, Tado Mona tells her to tell her children and grandchildren about what their father, Mona Rudo, did.

$$
\begin{aligned}
& \text { P-kla-i } \quad<n>\text { da-an na tama }=t a \quad \text { Mona Rudo. }(\text { RB 1:53:03 })^{3} \\
& \text { let-know-PF.IMP }<\text { PRF }>\text { cross-LF GEN dad }=1 \text { P.GEN Mona Rudo } \\
& \text { Let the deed of our father Mona Rudo be known. }
\end{aligned}
$$

Mona Rudo's deed was to lead the indigenous rebellion against Japanese colonial rule that Seediq Bale is about. The deed I want to tell you about is what Dakis Pawan and his colleagues have done in translating Seediq Bale, in trying to hand down Seediq to their children and grandchildren, and in adapting their tradition to modernity.

I am telling you about this deed to try to give back to the translators a fraction of what they have given me, starting in December 2011, when I emailed Iwan Pering after seeing her on a television talk show. When Iwan heard I was interested in the use of the Seediq language in the film, she sent me the Seediq translation of the shooting script. When she heard I was interested in gift culture, she taught me my first Seediq sentence, which I memorized as a string of syllables and only came to understand structurally a few years later:

$$
\begin{aligned}
& \text { Nii, } b<n>\text { ege na Pering. } \\
& \text { this }<\text { PF.PRF }>\text { give GEN Pering } \\
& \text { This is what was given by Pering. / This is Pering's gift. }
\end{aligned}
$$

I had asked Iwan how to translate "the hunter's gift" into Seediq. There is no way to say "hunter" in a single word in Seediq, so she thought of a hunter she knew. Her father, Pering, was a hunter. I hope Iwan won't mind if I model my own sentence on hers: Patis nii, bnege na Temu. This book is what was given by Temu. This book is Temu's gift, to the Seediq translators of Seediq Bale, to whom I dedicate this book.

Iwan Pering introduced me to the other translators: Watan Diro, Iwan Nawi, Pawan Nawi, Dakis Pawan, and Pawan Tanah. I will introduce you to Iwan Pering, 
Watan Diro, Pawan Nawi, and Dakis Pawan in the introduction. You'll get to know Pawan Tanah a bit later, at the end of chapter 1, and Iwan Nawi much later, in chapter 7. For the different roles they played in the translation of Seediq Bale, see table I.1.

All of the translators are towering heroes, but from my vantage point Dakis Pawan looms larger than the rest. Dakis Pawan spent months correcting actors' mispronunciations on the set of Seediq Bale, and about as long correcting my misunderstandings at his home in Puli. Dakis went over the Seediq screenplay with me line by line, and not just for the fee I paid him for his time. He gave me his time as a gift, a gift I can only begin to repay with this book.

I have gotten a lot out of Dakis's gift, including the present book. But somewhere along the way, the translation of Seediq Bale got under my skin, into my guts. I wasn't asking the questions, I was being interrogated. I had in my doctoral dissertation on the representation of Taiwan's indigenous peoples in film and fiction defended a liberal ideal of indigenous modernity. I was trying to persuade myself that modern indigenous people wanted to be like me. Meeting the translators of Seediq Bale has persuaded me I was wrong. I live ten time zones away from my hometown in Canada and would not want where I am from to define who I am. The translators want to stay right where they are, living in central Taiwan close to their alang, their village communities, which, to them, are an essential part of who they are. I want to create myself through my choices, while the translators' choices are informed by tradition, as the translators understand it. And today their tradition is disappearing.

Maybe because I am no longer quite so sure about who I am or want to be, I have found the Seediq translators' anxieties about the potential disappearance of their tradition profoundly unsettling, as if this would be the loss of something precious from the earth. And maybe because I myself have not had to take a stand, I have come to admire the Seediq translators for having dedicated their lives to the revitalization and, I would add, reinterpretation of their tradition. While I would not presume to stand beside them, the thought that I might contribute in some small way to their cause has sustained me.

Whatever contribution I might make is the crystallization of all the help I have received over the past eight years. I could not have done it without the help of the translators, to be sure, but I have some other gift-debts to gratefully acknowledge. I had four Seediq teachers. Another Pawan Nawi, Liu Te-hsing, who teaches at Fu Jen Catholic University, entertained me at Pawan's Garden just south of campus. Aking Nawi, who has been an educator her whole life, met with me at branches of the Milk King restaurant in Taipei. Professor Arthur Holmer guided me through Seediq grammar and offered me moral support. Temi Nawi welcomed my family into her home in Alang Gluban and told me a pair of haunting stories about the wider consequences of a failure to atone. I had the best teachers, though I haven't been the best student.

The same goes for me and my three Japanese teachers: Alex Huang, Ushi Kao, and Thomas Van Hoey. 
Many other colleagues have been model translators, scholars, and friends. I acknowledge some of you in the notes at the end of the chapters. My intellectual debts to many of you are also acknowledged in the main text and the index. For fear that I might leave someone out, I have decided not to list everyone; I hope to thank you in person! However, I would like to make a special mention of two role models: my doctoral adviser Johanna Liu and her husband, the late Vincent Shen, both of whom are shining examples of the "Taiwan spirit."

I am also obliged to the generous people at Ars Films for giving me a folder of files in the millions of megabytes and for putting me in touch with Yen Yun-nung, who told me about how he turned Seediq Bale into a novel, and with Su Jui-chin and Fumiko Osaka, who explained their approach to the subtitles.

And I am obliged to the generous taxpayers of Taiwan and Hong Kong who provided me with funding in the hundreds of thousands of dollars.

Thanks to Jayne Varney at Routledge for a cover design that suits the book. The color is right for a book about a film with lots of blood and cherry blossoms. The diamond pattern suggests either the alpine topography of Seediq territory or a weave called miri, where the diamonds represent the eyes of the ancestors watching their descendants to see if they are observing gaya, the moral law.

Thanks to Katie Peace for believing in the book and to my project manager Aruna Rajendran and production editors Samantha Phua, Naomi Hill, and Jacy Hui for staying patient and trying to keep me on schedule.

Editor and proofreader Jon Wilcox kept me consistent coming down the stretch.

I had two readers who read it so many times that it is their book, too. My former student Jessica Fan, now a doctoral student at the University of Texas at Austin, inspired me with ideas that my dear friend Jeff Lindstrom helped me refine.

Jeff was always there to suggest structural edits, and to do substantive editing, copy editing, and proofreading. If I have managed here and there to express myself clearly and concisely, it's because of Jeff.

All remaining errors of style, fact, or interpretation are entirely my own.

A final thanks to my family. My parents, John and Jane, read the manuscript appreciatively. My wife, Joey, has put up with me humming headhunting songs over and over again and taken good care of me. My daughter, who now has a Seediq name, Iwan Temu (my first name is her last name), has obliged me by answering klaun mu in reply to klaun su? What is known by her? What does she know? I hope it is that Seediq has a future in some form. Whatever form it takes is contingent upon indigenous cultural translation. 


\section{Phonology}

[] Phonetic form, for instance: [ $\int$ ino] is the pronunciation of sino.

// Phonological form, for instance: /sino/ is the mental representation of sino.

Since any romanization, besides the International Phonetic Alphabet (IPA), is based on an interpretation of the phonology of a language, I discuss romanization here. I use the standard romanizations for Japanese, Seediq, and Mandarin. The standard romanization for Japanese is modified Hepburn. Katakana, which I convert to modified Hepburn, was once used to represent Seediq (see ch. 3 sec. 2, ch. 4 sec. 1), but now there is a standard romanization.

The standard romanization for Seediq was developed by the linguist Paul Jenkuei Li based on the phonology (see Holmer 1996: 23-28) of Tgdaya, one of the three ${ }^{4}$ dialects of a language that is named Seediq after the pronunciation of the word for "person" in Tgdaya. Sediq and seejiq are the cognate pronunciations in the other two dialects, Toda and Truku. Beginning with the consonants, the /s/ in the Tgdaya word seediq is [s], but it is pronounced "sh" before /i/: sino, "wine," is [ ino]. In other words, $/ \mathrm{s} /$ is a phoneme with two allophones, [ $\left.\int\right]$ before $/ \mathrm{i} /$ and otherwise [s], as in Japanese, for instance "sushi." The /d/ is a [d], as it would be in English. The /q/ is an unvoiced, uvular stop, like an English " $k$ " except articulated farther back and unaspirated. (Try not to aspirate the $p, t$, and $k$-s in the line below.) As for the vowels, in careful speech, the two $e$-s would be separated by a glottal stop, so that seediq would be pronounced [se?ediq]. In rapid speech, the vowels might be combined, [sediq]. At any speed, the /i/ would weaken into an [I], because it is in an unstressed syllable with a final consonant. Words in Tgdaya take penultimate stress:

2 syllables: seediq ['sedıq], sino [' ' ino]

3 syllables: seediq [se' ?ediq], Mhebu [me'hebu]

4 syllables: Tgdaya [tugu' daya]

Vowels preceding the penultimate vowel are omitted from the romanization if predictable: if the initial in the penultimate syllable is a glottal stop or an $/ \mathrm{h} /$, the antepenultimate vowel assimilates; otherwise it is a $[\mathrm{u}]$. Hence: 


$\begin{array}{lllllll}\text { Pklai } & \text { ndaan } & \text { na } & \text { tama } & \text { ta } & \text { Mona } & \text { Rudo. } \\ \text { pu-ku-LA-yi } & n u-D A-a n & \text { na } & \text { TA-ma } & \text { ta } & \text { MO-na } & \text { RU-do. }\end{array}$

As for the romanization of Mandarin, I prefer Wade-Giles for my own literary translation (Sterk 2017), but I have deferred to Hanyu Pinyin, the most widely recognized romanization, in this monograph. Pinyin is pinyin, where the line over both vowels indicates the high, level tone. The other tone diacritics suggest the contours of the other three tones, like the descending tone in the second character in the word for "proud," 驕傲 jiāoào (see ch. $5 \mathrm{sec}$. 1). The IPA of jiāoào is $\left[\mathrm{tc}^{\mathrm{j}} \mathrm{a}^{\mathrm{w}}\right\rceil \mathrm{a}^{\mathrm{w}} \mathrm{V} \mathrm{W}$, where the [j] is a " $\mathrm{y}$ " sound and the ["] a hint of lip rounding at the end of the diphthong.

Note that I sometimes refer to a word in Pinyin as a transliteration, for instance: túténg is a transliteration of "totem." I mean túténg is a romanization of a transliteration, 圖騰, the characters used to approximate the sound of "totem" in Mandarin.

In using Pinyin for names, I hope I will not upset people like Chiu Juo-lung. Chiu Juo-lung is the Wade-Giles spelling, Qiu Ruolong the Pinyin spelling, of the noted comic book artist's name. I decided to call him Qiu Ruolong because that is how his name is spelled in English-language scholarship. My apologies to the subtitler Su Jui-chin, who is Jui-chin (Wade-Giles) in the acknowledgments and Ruiqin (Pinyin) in the main text, because I wanted to keep the main text consistent. I made exceptions for people who are already well known in English, such as Wei Te-sheng. However, I cited all Mandarin publications in Pinyin, for instance: Wei Desheng (Wei Te-sheng) (2000).

If two spellings of the same name weren't confusing enough, consider that Yiwan Nawi (I-wan Na-wei) is the Pinyin (and Wade-Giles) of a transliteration of Iwan Nawi, who used to be known in Mandarin as Huang Linghua (Huang Ling-hwa) (see Wei 2014 in the references below). If you ever get confused, visit the eResources at www.routledge.com/9780367198558 for an Excel file containing a list of all the people mentioned in the book. 


\section{Morphology}

- $\quad$ Affix boundary, as in kla-un and $p-k l a-i$, the PF and causative PF.IMP respectively of kela.

$<\quad$ An infix, for instance $b<n>$ ege, the PF.PRF of bege (give), and $<n>d a$-an, the LF.PRT of oda (cross).

* A reconstruction like *nayaw, the Proto-Austronesian root of which gaya is a reflex.

\section{Pronoun abbreviations}

1S first-person singular

2S second-person singular

1P first-person plural

$3 \mathrm{~S}$ third-person singular

2P second-person plural

3P third-person plural

Table 0.1 Seediq Pronouns

\begin{tabular}{lllll}
\hline Deixis/Number & Nominative & Genitive & Clitic nominative & Clitic genitive \\
\hline 1S & yaku & n-aku & $\mathrm{ku}$ & $\mathrm{mu}$ \\
2S & isu & n-isu & $\mathrm{su}$ & $\mathrm{su}$ \\
3S & heya & n-heya & & $\mathrm{na}$ \\
1P.IN & ita & n-ita & ta & ta \\
1P.EX & yami & n-nami & nami/miyan & nami/miyan \\
2P & yamu & n-namu & namu & namu \\
3P & dheya & n-dheya & & daha \\
\hline
\end{tabular}

IN and EX in table 0.1 are short for inclusive and exclusive respectively. If the interlocutor is included in "we," "us," or "our," one uses the inclusive pronoun. If not, then one uses the exclusive pronoun. In the interlinear analyses, I only label exclusive first-person plural pronouns as exclusive, not inclusive as such. Note that there are no clitic nominative pronouns for third-person singular and third-person plural. 


\section{Seediq focus abbreviations}

AF A verb in agent focus typically "focuses" an agent, meaning selects it as the subject, but might also focus an experiencer or a cause.

PF A verb in patient focus focuses a patient, that which is totally affected during an event; patient focus also implies future time.

LF A verb in location focus typically focuses a location, but often suggests a partitive interpretation of the subject.

IF A verb in instrument focus focuses an instrument (or a beneficiary or sometimes even a theme, that which moves in the course of an event).

Table 0.2 Tense-Aspect-Modality and Focus Affixes on Seediq Verbs

\begin{tabular}{lllll}
\hline TAM/Focus & Agent & Patient & Location & Instrument \\
\hline Present/Infinitive & $m-/<m>$ & $-u n$ & $-a n$ & $s-$ \\
Preterite (PRT) & $m n-/<m n>$ & $<n>$ & $<n>-a n$ & $s n-(?)$ \\
Future (FUT) & $m p-$ & RED- $-u n$ & RED- $-a n$ & $\emptyset / p$ - (?) \\
Imperative (IMP) & $\emptyset$ & $-i$ & $-i$ & - ani \\
Subjunctive (SBJ) & $m--a$ & $-o$ & $-e$ & - ane/-ano \\
\hline
\end{tabular}

Table 0.2 (cf. Holmer 2002: 335) is a formal analysis, an orderly presentation that mostly applies, but which a functionalist would want to revise. PF present implies future time, while PF future implies strong intent. I will indicate the function of a particular verb form when relevant. The affixes (prefixes, infixes, or suffixes) attach to roots or stems. The agent focus imperative, to which the agent focus affixes are added, is a stem derived from the patient focus form. For instance, $a d u k$ and ddupun are the agent focus imperative and the patient focus future forms of the same verb. The $k$ in $a d u k$ can be derived from the $p$ in ddupun, but not vice versa, ergo aduk is the stem and *dup is the root (see Holmer 1996: 26-27). Note that there is a distinction between proximal and distant future for agent focus, but as it did not come up in any of the analyses I have left it out of the table for the sake of simplicity. 


\section{Syntax}

$=$ A clitic boundary, for instance tama=ta, "our father," or kla-un=na, "known by her."

A word boundary in the gloss that does not reflect a boundary in the original term, like "hunting.ground" for $d-d u p-u n$, which is formally a PF future form.

\section{Word order abbreviations}

A basic Seediq clause might contain these elements: $\mathrm{V}=\mathrm{P}(\mathrm{NOM} / \mathrm{GEN})$ O NOM S:

$\mathrm{V} \quad$ Verb, which in Seediq can be AF, like the active voice in English, or non-AF, which is roughly like the passive voice.

$=\mathrm{P} \quad$ Pronoun that cliticizes (attaches) to the first verb in a clause to indicate the subject in an $\mathrm{AF}$ clause as a nominative (NOM) or the agent in a non-AF clause as a genitive (GEN).

O Object, that which gets "verbed."

NOM Nominative, a $k a$ that usually marks the following phrase as the subject. $\mathrm{S} \quad$ Subject, typically the agent in an AF sentence and the patient, location, or instrument in a non-AF sentence.

Consider the following active/passive pair of sentences, presented in four lines. Top to bottom, the four lines present phonology, morphology, syntax, and translation:

$\begin{array}{lllll}M<n>\text { imah } & =k u & \text { sino } & k a & \text { yaku. } \\ \mathrm{AF}<\mathrm{PRF}>\text { drink } & =1 \text { S.NOM } & \text { wine } & \text { NOM } & 1 \mathrm{~s} . \mathrm{NOM} \\ \mathrm{v}(\mathrm{ACTIVE}) & =\text { P.NOM } & \text { o } & \text { NOM } & \mathrm{s}\end{array}$

I drank some wine.

$<N>$ mah-an $=m u \quad k a$ sino.

$<$ PRF $>$ drink-LF $=3$ S.GEN NOM wine

$\mathrm{V}$ (PASSIVE) $\quad=$ P.GEN NOM $\mathrm{S}$

Some of the wine was drunk by me. 
From this pair, you can see that definiteness (wine vs. the wine) is one criterion in focus selection and that the basic order for Seediq is VOS, a rare order globally (Hammarström 2016). For trends in translation from SVO Mandarin to VOS Seediq, see chapter $2 .^{5}$

\section{Other grammatical abbreviations}

ACC Accusative, herein the $o$ object marker in Japanese and the accusative use of Seediq nominative pronouns.

ADJ Adjective, a word or phrase that modifies a noun phrase.

ADV Adverb, a time or space word or phrase; what would be manner adverbs in English are often verbs in Seediq.

AUX Auxiliary verb, for instance, asi in Seediq is a modal auxiliary, while wada is perfective (PRF).

CL Classifier, a kind of determiner that "classifies" nouns, for instance, 條 tiáo in Mandarin, for long, thin things like rivers or lives.

CMP Complementizer, the head of a clause inside a clause, such as "that," 說 shuō, or mesa.

COP Copula, a linking verb like the be-verb in English.

GER Gerund, a kind of nominalized verb, for example "headhunting" derives from "to headhunt."

INT Interjection, a word like "eh" in Canadian English that can stand alone or appear at the end of a clause, used herein mostly for sentence-final particles in Mandarin and Seediq, but also for prosodic "vocables."

NEG Negative, where Mandarin and Seediq use different negative words depending on the relative time of the event and whether a noun or verb phrase is being negated.

PL Plural, used herein mostly for the Mandarin "collective" suffix 們 mén.

PRF Perfect or perfective aspect, an "external" view of an event as completed, where the perfect (I have eaten) is currently relevant and the perfective (I ate) is simply over, and where the perfective may be termed the preterite if it implies past time.

PRG Progressive aspect, an "internal" view of an event as ongoing.

REC Reciprocal, a prefix for reciprocity, such as $m d$-dahun, to reconcile with one another.

RED Reduplication, where part of a word is duplicated, herein to imply numerousness.

TOP Topic, what a clause is about. ${ }^{6}$ 


\section{Notes}

1 With regard to the web metaphor, Geertz described "man" as "suspended in webs of significance he himself has spun" (1973: 5). Note that Geertz was writing decades before the internet was invented. He was thinking of a metaphorical spider's web. Just as spiders spin webs of silk to catch dinner, so we spin webs of significance to capture meaning. Geertz cited the aptly named sociologist Max Weber for the web metaphor, but Wilhelm von Humboldt had, several generations earlier, used the metaphor of spinning a web in his discussion of language: "By the same act whereby [man] spins language out of himself, he spins himself into it, and every language draws about the people that possess it a circle whence it is possible to exit only by stepping over at once into the circle of another one" (Humboldt 1989 [1836]: 60, cited in Leavitt 2011: 93). Alas, as Humboldt went on to note, it is hard for adults to learn a second language; most of us are confined to the circle of the web of our mother tongue. I take the point that we have to understand in some language or other, but in invoking the metaphor of the web-spinning spider we can at least stress human artfulness in meaning-making by noting that spiders do not get caught in their own webs.

2 The translation of Seediq Bale has been treated as a case of subtitling by Elaine Lee (Lee 2016). According to Lee, the English translation was "a relay translation through the Mandarin" from "the original dialogue in Seediq and Japanese" (2016: 59). Parts of the screenplay had been translated from Seediq, but to describe the screenplay as a whole as a Seediq-Mandarin translation is misleading.

3 I cite from the four-and-a-half hour long version of Warriors of the Rainbow: Seediq Bale on the Blu-ray disc distributed by Well Go USA. The film is in two parts, The Sun Flag and The Rainbow Bridge. Depending on the format, device, and program you use, you may get slightly different times. The time codes I provide should be understood as prefaced with a tilde, especially because I cite from the beginning of the subtitle. For instance, $R B$ 1:53:03 means $R B \sim 1: 53: 03$, starting within a few seconds of 1:53:03 of The Rainbow Bridge.

4 There are three dialects according to Seediq people today, and three written standards, but the differences between Toda and Truku are so slight that a two-dialect analysis is persuasive. On the other hand, there were, and to some extent still are, linguistic differences between villages that might justify analytical balkanization.

5 My approach to Tgdaya is based on Arthur Holmer's work. Tsukida Naomi's take on Truku is an alternative perspective (Tsukida 2005). For instance, instead of "focus," Tsukida uses "voice," as in active and passive voice. For my own approach to analyzing Mandarin, see Sterk 2018.

6 To explore the phonology, morphology, and syntax of the Seediq language on your own, please visit the eResources at www.routledge.com/9780367198558.

\section{References}

Appiah, Kwame Anthony (2012 [1993]) “Thick Translation," in Lawrence Venuti (ed), The Translation Studies Reader, 3rd edition, New York: Routledge, 331-343.

Geertz, Clifford (1973) "Thick Description: Toward an Interpretative Theory of Culture," in The Interpretation of Cultures, New York: Basic Books, 3-30.

Hammarström, H. (2016) "Linguistic Diversity and Language Evolution," Journal of Language Evolution, 1.1: 19-29.

Holmer, Arthur J. (1996) A Parametric Grammar of Seediq, Lund, Sweden: Lund University Press. 
Holmer, Arthur J. (2002) "The Morphology and Syntax of Seediq Focus," in Fay Wouk and Malcom Ross (eds), The History and Typology of Western Austronesian Voice Systems, Canberra, Australia: Pacific Linguistics, 333-354.

Humboldt, Wilhelm von; Michael Losonsky (ed); Peter Heath (trans) (1989 [1836]) On Language: On the Diversity of Human Language Construction and Its Influence on the Mental Development of the Human Species, Cambridge: Cambridge University Press.

Leavitt, John (2011) Linguistic Relativities: Language Diversity and Modern Thought, Cambridge: Cambridge University Press.

Lee, Tzu-yi Elaine (2016) "The Subtitling of Indigenous Values in the Film Seediq Bale," Other Modernities, Special Issue (February): 58-67.

Sterk, Darryl (2017) “Translator's Note," in Wu Ming-Yi (ed), The Stolen Bicycle, Melbourne, Australia: The Text Publishing Company, 373-376.

Sterk, Darryl (2018) “The Grammatical Artistry of Chinese-English Translation," in Chris Shei and Zhao-Ming Gao (eds), The Routledge Handbook of Chinese Translation, London and New York: Routledge, 129-146.

Sturge, Kate (2007) Representing Others: Translation, Ethnography and the Museum, Manchester: St. Jerome.

Tsukida, Naomi (2005) "Seediq," in Alexander Adelaar and Nikolaus P. Himmelmann (eds), The Austronesian Languages of Asia and Madagascar, London and New York: Routledge, 291-325.

Wei Desheng (Wei Te-sheng) (2000) Saideke Balai (Seediq Bale), Taibei: Xinwenju (Government Information Office).

Wei Desheng (Wei Te-sheng); Yiwan Nawei (Iwan Nawi) (trans) (2014) Kari Toda Patas eyga Sediq balay (The Toda Language Screenplay for Seediq Bale)/Saideke Balai Saidekeyu Jubenshu (Seediq-Language Screenplay for Seediq Bale), Taibei: Yushan. 
$\Longrightarrow$ Taylor \& Francis Taylor \& Francis Group http://taylorandfrancis.com 


\section{Introduction}

\section{Indigenous modernity and the translation of Seediq Bale}

This book is a study of the role translation played in the textual history of the screenplay of the Taiwanese blockbuster Seediq Bale (directed by Wei Te-sheng, 2011). This film is about the Musha Incident, an indigenous ${ }^{1}$ rebellion in 1930 against Japanese colonial rule. Seediq Bale is an interesting case for translation studies because it was filmed in translation. Most of the dialogue was translated from Mandarin, the language of the screenwriter, into Seediq, the language of the rebels. Seediq Bale is particularly interesting because some of the dialogue had been translated from Seediq into Mandarin. In fact, the screenplay has a centurylong textual history in which translation - both interlingual translation between Japanese, Mandarin, and Seediq and also intralingual "translation" between the three Seediq dialects, Tgdaya, Toda, and Truku - played an important part.

As you can tell from table I.1, the headhunting song Sayama Yūkichi published in Truku Seejiq in 1917 was "backtranslated" into Tgdaya Seediq by Dakis Pawan and his colleagues in 2009. Between 1917 and 2009, the Seediq people had

Table I.1 Timeline of Translation in the Textual History of the Screenplay of Seediq Bale

1917 Sayama Yūkichi recorded an east coast Truku headhunting song in katakana and translated it into Japanese (see ch. 4).

1935 Asai Erin recorded an east coast Truku story about the soul's passage to the afterlife in IPA and translated it into Japanese (see ch. 3).

1990 Qiu Ruolong published a comic book (Qiu 2011 [1990]) in Mandarin about the Musha Incident based on interviews with witnesses (see ch. 1).

1998 Qiu Ruolong released a documentary, $\mathrm{Ga}$ Ya, consisting of witness interviews that were translated from Seediq into Mandarin by Pawan Tanah (see ch. 1).

1998 Pawan Tanah translated the 1917 song and the 1935 story into Mandarin (chs. 3-4) in a book (Bawan 1998) about Seediq culture (see chs. 5-6).

2000 Wei Te-sheng based Saideke Balai, the only published version of his Mandarinlanguage screenplay (Wei 2000), on Qiu's comic and Pawan Tanah's book.

2003 Dakis Pawan translated a few lines from the published screenplay into Tgdaya for a short film, a medley of the main scenes from the screenplay (see ch. 1).

2009 In August, Dakis Pawan and Watan Diro translated the "shooting script" - a revision of Wei's screenplay - into Tgdaya and Toda (see ch. 2).

2009 In September, Dakis Pawan revised his Tgdaya translation with Iwan Pering and Pawan Nawi to produce the "Seediq shooting script" (see ch. 2).

2014 Iwan Nawi, Qiu Ruolong's wife, published a Toda Sediq translation (Wei 2014) of the Seediq lines from the published screenplay (Wei 2000) (see ch. 7). 


\section{Introduction}

crossed a fuzzy boundary into modernity. When you compare the original song to the backtranslation, the modernity of the latter shows, as I will discuss in detail in chapter 4 . Here in the introduction, I will argue that in general the textual history of the screenplay can be discussed in terms of "indigenous modernity," a term that Paul Barclay has proposed in a recent study of the Musha Incident.

\section{The Musha Incident, Seediq Bale, indigenous modernity, translation}

On the morning of October 27, 1930, "headhunters" from six of the twelve Tgdaya Seediq villages in central Taiwan hastened to the hill station of Musha and poured into the venue for a joint athletics meet. The meet was a major event in Japanese colonial society; various officials were attending. Many of these officials were killed. In total, 134 Japanese men, women, and children were decapitated, speared, or shot. Two Han Taiwanese were also killed by accident. During the Japanese reprisal, headhunters from two closely related groups called the Toda Sediq and the Truku Seejiq were hired as mercenaries. The Toda and Truku mercenaries were to bring back as many Tgdaya heads as they could, and they would be paid by the head. Eighty-seven heads were brought back during the reprisal (Deng 2000: 107). Another 101 Tgdaya heads got hunted in the Second Musha Incident, in which Toda warriors were allowed to have a go at the Tgdaya survivors of the reprisal, who were being housed unarmed in two refuges, in the middle of the night on April 25, 1931.

In an article about what was retroactively the First Musha Incident that was published right around the time of the second, a Japanese military official described the incident as "more dorama than dorama" (Hattori 1981 [1931]: v. 2 561), where dorama is the Japanese pronunciation of "drama." The official was not just remarking that truth is stranger than fiction. He was also trying to inspire his Japanese readers with the intensity of patriotism the Tgdaya Seediq rebels had displayed. He was holding the rebels up as role models. He was also hoping to keep taking advantage of them. The Japanese had been taking advantage of the Seediq before the rebellion by forcing young men to cut down "the trees that had seen [their] ancestors," as a corvée laborer named Watan puts it in Seediq Bale (SF 41:45). Excessive corvée labor was one of the reasons why the rebellion occurred. The Japanese would continue to take advantage of the Seediq until 1945: sons of Tgdaya rebels and of Toda and Truku collaborators were strongly encouraged to volunteer to fight for Emperor Hirohito, and many of them did.

After Hirohito surrendered in 1945, another colonizer took over, the KMT (Kuomintang)-controlled ROC (Republic of China). Now the Musha Incident was the Wushe Incident: Musha is pronounced Wushe in Mandarin (but for consistency I will continue to use the Japanese romanization to refer to the incident). The Kuomintang appropriated the incident for propaganda, re-narrating it as an episode in the Chinese national resistance against the Japanese. The ghost of Mona Rudo, the chief who led the rebellion, was drafted into the Chinese nationalist army. Wei Te-sheng, the screenwriter-director of Seediq Bale, is no Chinese nationalist, 
however. He is a Taiwanese nationalist, and Taiwanese nationalists, like Chinese nationalists before them, have appropriated the Musha Incident, interpreting it as a national allegory (see ch. 1).

Whether or not you view Seediq Bale as a Taiwanese national allegory, the importance of the film seems self-evident in Taiwan. It was not just a blockbuster when it was released in two halves - The Sun Flag and The Rainbow Bridge - in September 2011; it was the biggest film in Taiwan film history in both budget and box office. Based on the box office, a tenth of Taiwan's population of twentythree million must have seen it in the fall of 2011, and almost as many saw The Rainbow Bridge as had seen The Sun Flag. Seeing it felt like participating in a national movement to help the film make back its budget. It was not just popular but also acclaimed, winning the 48th Golden Horse Award for Best Picture. It even made it onto the global stage when it debuted at the 68th Venice Film Festival. Briefly, under the title Warriors of the Rainbow (because the Seediq believed that a man who had headhunted had the right to cross a "rainbow bridge" into the afterlife), Seediq Bale, which means "true people" or "true Seediq," represented Taiwan internationally.

An international film audience might wonder what all the fuss was about: the international cut had to be shortened so much to make the two-and-a-half-hour time limit at Venice that it was hard to follow, and at that length it was monotonously violent, lacking the alternation of fast and slow of the four-and-a-half-hour domestic cut. The domestic cut is much better. It is worth seeing. But I am less interested in it as a work of film art than in what it is about.

According to Paul Barclay, the Musha Incident was not just a case of ruthless suppression of violent anticolonial rebellion, but also a "turning [point]" (2017: $49)$ in colonial rule that is significant in terms of "indigenous modernity" (13, 33-38). The incident marks a transition to modern state rule in Taiwan's indigenous territory. Thirty-five years before, at the beginning of the Japanese colonial era in 1895, Mona Rudo's father's generation still lived a stateless lifestyle of marginal semi-autarkic independence à la Zomia (Scott 2009). A few years later, Seediq headmen conducted diplomacy with Japanese "representatives" of one kind or another by drinking cheek to cheek with them on the frontier. In Barclay's terms, this was "wet" diplomacy, where international relations were personalized and lubricated.

Consider, then, an altercation (Barclay 2017: 43-44) that was another of the immediate causes of the rebellion in 1930. At the corvée laborer Watan's wedding three weeks before the attack, Mona Rudo's son Tado Mona tried to treat Japanese patrolman Yoshimura Katsumi to a drink, assuming the rules of wet diplomacy still applied. Yoshimura refused, and a brawl ensued. Chief Mona tried to apologize the next day by offering the patrolman's boss Sugiura Kōichi alcohol, but he was rebuffed. Mona did not realize that the rules had changed, the game had changed. By 1930, there was a durai (dry) (44) SOP (Standard Operating Procedure) for fungible Japanese functionaries like Yoshimura and Sugiura to follow - and follow it they did: the case had already been reported up the chain of command as an 


\section{Introduction}

assault of an officer. Mona Rudo was in big trouble. Barclay's point is not that we can understand Mona's reason for rebellion but that state-Seediq relations were no longer international, personalized, or lubricated. By 1930, the GovernmentGeneral was phasing the chiefs out.

Partly in response to the Musha Incident, the authorities "solidified the standing of the indigenous territory as a separate entity" (Barclay 2017: 31). Before the Japanese arrived, the indigenous territory in the island's mountainous interior was a blank on a map. The Japanese were the first to conquer it, but they kept it separate as a sub-territory for resource extraction, not for civilization. Building on the work of the historian Thongchai Winichakul, Barclay terms such internal territories second-order geobodies (190-249) and describes them as "mottl[ing] the ideally solid surfaces of the international system's geobodies" (13). As Barclay explains, the Japanese also sub-divided Taiwan's indigenous territory into what might be termed third-order geobodies, each one "belonging" to linguistically and culturally defined indigenous groups like the Seediq.

After 1945, the Kuomintang "maintained the ethnically bifurcated form of rule" (248) whereby the Chinese plains were kept administratively separate from the indigenous mountains. The indigenous territory (the second-order geobody) persisted for four decades under martial law. But after the lifting of martial law in 1987, and with growing momentum in the 1990s and 2000s (see endnote 1 below), the sub-territories (the third-order geobodies) became the bases for indigenous territorial claims (249). Indigenous groups like the Seediq could cite colonial maps (7-8) to claim that their traditional territories had been outlined by Japanese cartographers, and they could cite colonial ethnographies to claim they were culturally distinct. Such claims were hardly necessary when these groups were stateless. Given that they were made a century after the Japanese brought colonial modernity to the indigenous territory, such claims were modern. But indigenous modernity in Taiwan should not therefore be dated to the late 20th century. If local indigenous claims are the flowering of an "unfolding political dynamic" (Simon 2015: 75, cited in Barclay 2017: 251 note 6) that predates the Kuomintang's arrival in 1945 by decades, then indigenous modernity in Taiwan is a century old.

I find this account of the origins of indigenous modernity persuasive. It provides a background to a well-known account of the origins of global indigeneity in the 1960s, when, according to Ronald Niezen (2003), indigenous activists around the world made a common cause by raising the banner of human rights. But my own interest is the everyday subjectivity of modern indigenous people today. I am interested in how the modern indigenous people I study in this book understand themselves as bilingual biculturals, as citizens of a modern state and inheritors of an indigenous tradition. I wonder how they know their tradition and how they might "translate" it into an alternative indigenous modernity that might be distinctive both as a way of knowing and as a way of life, particularly in relation to their interlingual translational practice. Indeed, I assume that interlingual translation is one of the ways in which they have translated tradition. It is partly in translating cultural documents between Japanese, Mandarin, and different dialects of Seediq 
that Seediq people have developed an idea of what their tradition is and a sense of its relevance to their lives today.

Seediq Bale is important in this context because it was filmed in translation. Wei Te-sheng was just trying to make his film appear historically authentic when he had his Mandarin-language screenplay team-translated into Seediq. He did not know what he was getting himself into. Two members of the translation team were grandchildren of Tgdaya Seediq rebels, one was from a noncombatant village, and one was from a Toda village. There was a lot of dorama, a lot of "drama," in the translation process.

Indeed, the Mandarin-Seediq translators often rebelled against Wei Te-sheng in their translation. In his screenplay, Wei had explained the rebellion in Seediq cultural terms - for instance, that Mona Rudo wanted to give young Tgdaya "braves" the chance to headhunt, which would give them the right to cross the Rainbow Bridge into the afterlife - but the translators sometimes substituted their own explanation (see ch. 5). Being peaceable, the translators expressed themselves not through violent rebellion but in terms of correction: they told me they were rectifying Wei Te-sheng's misrepresentations. But when I compared their translations to their accounts of the linguistic and cultural backgrounds, I discovered inconsistencies and disagreements. What one translator said sometimes did not match what another translator said or what was written in the translation.

As I will discuss in detail in the next section, it is no surprise that the translators might disagree with one another about their traditional culture, which was and is still relatively abstand, unstandardized. To the extent they can agree on what their culture was and is, Seediq people today might disagree about the relevance of tradition. They might have different ideas about how to "translate" tradition into an alternative modernity.

Seediq modernity is partly a standardization of Seediq language and culture that will be easier to "revitalize." Seediq needs revitalization as a language because it is endangered. It is spoken by well under ten thousand people. More importantly, it is spoken at varying levels of fluency as a function of age: it really is a mother tongue, often a grandmother tongue. A study (Chen 2010) of Atayal, a closely related language, found communities at six or seven on Fishman's Graded Intergenerational Disruption Scale, which only has eight levels.

Seediq culture is also endangered, but it has by necessity been reinterpreted. As Christians living in a modern state, the Seediq have had to reconsider certain cultural practices. There can be no revival of headhunting, except as a political metaphor (see ch. 4). Headhunting aside, what Seediq culture means today is up to Seediq people to decide as citizens of the Republic of China. The Republic of China has had an "indigenous" policy since the 1990s, as part of a shift to official multiculturalism. Though the Seediq and other indigenous peoples were not the intended primary beneficiaries of the policy of multiculturalism, which was in part an attempt by Taiwan's political elites, particularly the Kuomintang, to pivot to democracy after four decades of martial law, they have benefited from it (Friedman 2018: 79), and they are now 


\section{Introduction}

revitalizing their reinterpretations of their cultures within the multicultural framework.

The reinterpretation of Seediq culture is part of the textual history of the screenplay of Seediq Bale, most obviously when the translation was a backtranslation. When Mandarin translations of Seediq texts recorded by Japanese ethnographers and linguists (see table I.1) that Wei Te-sheng had incorporated into his screenplay were backtranslated into Seediq, they ended up very different, because the translators are not the people their grandparents were. Their grandparents were "traditional," while the translators are "modern." In this monograph I excavate the screenplay of Seediq Bale to trace the translational process, which is more a story of adaptation than rebellion, that has been producing Seediq modernity.

In the next section, I describe my approach to the excavation by considering the conditions of indigenous translation in more detail. The section after that suggests how the evidence I excavated supports the claims I make, both local and general. At the end, there is an overview of the book that is followed, in the endnotes, by definitions of my keywords.

\section{The study of Seediq cultural translation and the translators who do it}

While an historian might begin a study of Seediq culture with colonial records, and an anthropologist with fieldwork, my own starting point was how the translators of Seediq Bale translated and what they have said or written about the cultural background to their translation. Anyone who approaches culture linguistically like I have done has to keep the following caveat in mind: philology, by which I mean language use, is not necessarily cultural ontology, by which I mean a cultural model of the world as it is and should be. Philology is not ontology is an encapsulation of the cultural anthropologist Roger Keesing's caution about "the dangers of overinterpretation - the attribution of nonexistent theologies and metaphysics - by ethnographers" (1985: 201). Keesing was cautioning ethnographers who might read theologies and metaphysics, which I call "ontology," into "conventional metaphors." For instance, in Seediq the "future" is bobo na, literally "its above." Does that imply that the Seediq see themselves as rising up through time? I like to think so, but if FUTURE IS UP is a dead metaphor, then it might not offer us much insight into Seediq culture. Allow me to build on Keesing's caution: we should not assume that anything anyone says is a transparent externalization of his or her beliefs about the world. We all use language in order to state our beliefs about the world, to be sure, but we also use language to dissuade, persuade, lie, and justify, attempting rhetorical maneuvers around our desires and fears, our pride and our principles.

There is an example of such rhetorical maneuvering in the production of Seediq Bale, concerning the scene in which Mona Rudo shoots his wife Bakan Walis to spare her suffering at the hands of the Japanese ( $R B$ 1:42:44). The scene was translated by Dakis Pawan, the chief translator, in August 2009, and revised by Dakis with co-translators Pawan Nawi and Iwan Pering in September 2009, without 
incident. Then, on April 29, 2010, six months into the shoot, Dakis Pawan told the director Wei Te-sheng that it might be "dangerous" to film the scene as scripted (Wei 2011: 201) because it went against gaya, a Seediq keyword that we can for the time being gloss as Seediq cultural ontology (cf. ch. 5 sec. 3). Wei Tesheng replied that as scripted the scene had "dramatic tension" and the capacity to "shock" the audience (Wei 2011:202). He could have added that the shooting was attested in the colonial record (Fubu 2002 [1931]: 765). And Wei's explanation of why Mona did it is plausible. In the end Wei revised the scene to Dakis's satisfaction: Wei would shoot Mona firing his gun, then cut to black without showing the impact of the bullet. However, satisfying Dakis did not mean satisfying Dakis's co-translator Iwan Pering. In an interview with Taiwan Indigenous Television (TITV) in June 2010, and in another interview with the Atayal documentary filmmaker Pilin Yapu (in Musha Kawanakajima, 2013), Iwan claimed that Mona would never have gone against gaya, and that Wei should never have included such a scene.

With all due respect to Iwan, even if there was a unanimous Seediq consensus on the morality of a husband shooting his wife, even in extremis, making what people say and what people believe identical in this case, what people believe is not always the same as what people do. Philology may sometimes reflect ontology, but ontology is not always human ethology.

If we keep the caveat that philology is not ontology is not ethology in mind, along with the related caveat that sometimes philology might affect ontology, which conditions ethology, then a linguistic approach to culture seems capacious enough, as we can all talk about anything in life, or in the universe, in any language (cf. ch. 7 and the conclusion sec. 3). Certainly, we can discuss Seediq culture in English, as I am doing in this book. But, in translation studies terms, our discussions are doomed to be "domesticating" - understanding people from a different culture on our terms, not theirs - unless we can make reference to the language in which the culture was and to a certain extent still is lived. Hence, when I use the term culture, the reader can silently preface it with linguistic. As I see it, language and culture are of the same cloth, which is not to say that if you pull a particular thread you can be sure how the cloth will twist.

As native speakers of Seediq, the translators of Seediq Bale can try to claim to be experts, as if they have objective knowledge of their culture. To the extent that matters of culture are social facts, the translators do have some basis for a claim of objectivity. But their objectivity is also supposed to extend to the past. Dakis Pawan, the chief translator of Seediq Bale, has published two books about Seediq Bale, not about its translation but about the history of the Musha Incident and the Seediq people. The first book is called Truth Bale (Guo 2011), which literally means "true truth" (as opposed to the other kind?), and the second is called Seeing the Truth Again (Guo 2012), about his face-to-face interviews with survivors of the incident. In his books, and in person, Dakis Pawan sometimes makes apparently iron-clad truth claims based on his putatively objective knowledge of history. The indigenous scholar Nakao Eki Pacidal, who is Amis not Seediq, argues that Dakis's claims go beyond fact to broach historical interpretation (Pacidal 


\section{Introduction}

2012: 177). I would point out in this regard Dakis's own admission that we simply do not know if Mona Rudo's first headhunt was against an Atayal or a Bunun village community. Both possibilities are attested in his oral history research (Guo 2011: 150).

In admitting his ignorance here, Dakis Pawan reveals that he has a recognizable idea of empiricism. ${ }^{3}$ Dakis is not epistemologically hegemonic. He acknowledges that there are truths of Seediq history that are rashomonic. To some extent Dakis's "truth" was the person he was interviewing. His interviewee was right there in front of him, a human presence, bearing witness. After over half a century, the facts of the Musha Incident are harder to know, let alone the truths of precolonial Seediq culture.

How indeed was Dakis Pawan to know what precolonial Seediq culture was like when his sources included Japanese linguists and ethnographers, outsiders who brought their own assumptions and aims to the research enterprise? Linguists such as Asai Erin (see ch. 3) came to central and eastern Taiwan and found people who seemed to speak the same language, to which a name was given, the word for person. Today the language is spelled "Seediq," after the pronunciation of the word for person in the Tgdaya dialect. Ethnographers such as Sayama Yükichi (see ch. 4) agreed that the speakers of this language shared a culture, but other ethnographers lumped the Seediq with the Atayal, and it was lumpers who persuaded the colonial bureaucrats who carved the second-order geobody into third-order geobodies. Not that it mattered how the lines were drawn, because the indigenous territory and the sub-territories it contained no longer belonged to the indigenous people. To the authorities, it was all Japanese territory, and the governor-general's aim was to rule it peacefully and profitably. Anything linguists and ethnographers could discover might help advance that aim.

The evidence Japanese linguists and ethnographers gathered is evidence, but there is often no way of triangulating it (verifying it independently), except against the village community experience of people such as Tiwas Pawan, a witness to the Musha Incident with whom Dakis Pawan consulted until her death in 1997. Dakis Pawan could also triangulate colonial evidence against his own village community experience. The problem is that the village community had been under Japanese colonial rule for thirty-eight years and Chinese colonial rule for nine years by the time Dakis was born into it in 1954, and people like Dakis describe having to reacquaint themselves with Seediq culture, to learn for the first time as adults about Seediq historical events like the Musha Incident, and to brush up their language skills after significant time away from home.

It is no surprise, then, that people like Dakis Pawan and Iwan Pering often disagree about the past: they are of the present, not of the past - a past that was, moreover, culturally more varied than they may realize. There was never a singular Seediq culture, a stable, bounded grid of static objects of knowledge; in fact, "Seediq" culture has always been a shifting constellation of moving targets interacting with other such constellations - constellations that can be understood as suites of evolving adaptations to changing eco-social milieux. Whether a husband can shoot his wife in extremis was cited earlier as an example of the challenge of 
studying culture and practice through language when the relationships between language, culture, and practice tend not to spell out predictably at the best of times, much less for a relatively abstand case when a hundred years have passed. There is another example of the same challenge in the translation of the screenplay, and it is this example, as it happens, that got me started on this project.

Seediq warriors in Seediq Bale apparently use a Seediq word that means "flee!" The Mandarin word that appears in the subtitles is 逃 táo, meaning, roughly, "flee." The translation of táo in both Tgdaya and Toda is usually qduriq. But qduriq has to be used carefully. In the first conversation I ever had with Iwan Pering, she told me that according to her fieldwork with a circle of hunters in her home village of Meixi, you can tell the enemy to qduriq or say that you saw the enemy qduriq, but when the enemy presses near, whatever you do, you had better not tell your brothers in arms to qduriq or to admit later on that qduriq is what you did. The hunters Iwan Pering consulted think it is shameful for a warrior to qduriq. A real warrior would stand and fight, not flee. Therefore it would appear that the use of táo in the subtitles contravenes the ethos of a Seediq warrior.

The first time táo is used in the subtitles is during the scene where a Tgdaya trading party meets a group of Bunun braves in 1903 to try to break the embargo that has been imposed on the Seediq since 1897, when the members of an expedition to find a cross-island railway route (Barclay 2017: 95) were massacred in Seediqland (see table 1.1 for a historical timeline of the film). That night, the Bunun, who have been bought off by the Japanese, start killing the Tgdaya as they sleep. Right before the Bunun chief tries to impale Mona Rudo, Mona opens his eyes and makes his escape. Mona yells “quick, flee!” (快逃 kuài táo!). In his initial translation in August 2009, Dakis Pawan translated kuài táo! into qduriq, nahari! meaning "flee, hurry!" When I saw this translation, I wondered whether Dakis Pawan thought it was acceptable for Mona to say qduriq in this circumstance. Then I noticed that in the final cut Mona hollers Tutuy, neelu hari!, meaning "Wake up (or get up), hit the road, hurry!" (SF 29:31). Why the change? Dakis Pawan changed it in the middle of September 2009, after hearing about Iwan Pering's fieldwork.

But elsewhere táo ended up getting translated into qduriq. As the Tgdaya warriors flee home to the village of Mhebu, for instance, Mona Rudo's father Rudo Luhe shouts qduriq! (SF 34:57). Mona's father was played by Pawan Nawi, who helped revise the Tgdaya translation in September 2009. When I asked Pawan Nawi about his use of qduriq in the film, he told me that Iwan Pering, being a woman, might not know how a warrior would have spoken or conducted himself, nor would Dakis Pawan, who is not a hunter. According to Pawan Nawi, who is himself neither a hunter nor a warrior but who apparently believes he knows how a warrior would have acted and spoken over a century ago, there is nothing wrong with shouting qduriq. In many situations, whether in hunting or in battle, it would be imbecilic not to shout qduriq. This is not to say that shouting qduriq is fine for everyone. It is not fine for the hunters Iwan Pering consulted. It is to say that it seems fine for some, and therefore hard to know whether Wei Te-sheng misunderstood or 
misrepresented "Seediq culture" in the first decade of the 20th century in this specific place.

In this case, the Seediq can only agree to disagree, though it seems to me they should be able to agree that there is no way to know and that it depends on who, when, and where. Even for current conditions, agreement on Seediq culture might still be difficult because it is still quite variable. It is still mostly based on convention. It is relatively unstandardized. It is, as sociolinguists say, abstand, varying from person to person and place to place to a much greater degree than any ausbau or standardized culture. ${ }^{4}$ While in premodern times there was a strong pressure toward "conventionalization" within villages and to some extent within village alliances, there might, nonetheless, be significant cultural differences a few miles upriver in the next village.

A Seediq person's background a century ago was the village he or she was from, and indeed the four translators who worked on the translation of the Tgdaya and Toda dialogue for Seediq Bale come from different villages (visit the eResources for an online map). Three of the translators translated from Mandarin to Tgdaya Seediq: Dakis Pawan, Pawan Nawi, and Iwan Pering. Dakis Pawan grew up in Gluban, the Seediq name for Kawanakajima, the place where the survivors from the six rebellious Tgdaya villages were moved in 1931, which was renamed Qingliu after the war. Dakis's folks were originally from Mhebu, Mona Rudo's village. Pawan Nawi also grew up in Gluban, but his folks were originally from another rebellious village, Drodux. Iwan Pering grew up in Meixi, a village on the way from Wushe to Puli, the largest town in the area. Meixi contains two Tgdaya village communities, the only ones that were not eventually relocated by the Japanese. (The residents of Paran and other noncombatant Tgdaya villages were moved to a village called Nakahara in the mid-1930s to make way for a reservoir.) Watan Diro, who translated the screenplay from Mandarin to Toda Sediq, grew up in Gungu, which was a Tgdaya village up to 1930, but has been a Toda one ever since. However, place of origin, along with "sub-ethnicity" (Tgdaya versus Toda), is now only part of a Seediq person's identity.

Agreement on Seediq culture is also difficult because Seediq people's biographies differ in more dimensions than they did before. Dakis Pawan (Guo 2011: 32-34) went to the National Taiwan Normal University in Taipei and came back to teach mechanics in Puli at the local trade college. A liver ailment in the late 1980s introduced him to Deng Xiangyang, who ran a medical testing lab in Puli and researched the Musha Incident in his spare time. Deng encouraged Dakis to start interviewing elders in Gluban, a task that Dakis threw himself into because he realized he did not know who he was and wanted to find out by learning from the elders, who knew his ancestors. Since then, Dakis has become the main Seediq-language expert. He helped the linguist Song Limei compile the Seediq dictionary that has been online since February 2016.

Pawan Nawi is a farmer and handyman who, in his own words, has done "rough," meaning "heavy labor," his whole life. Videogenic, with great presence and voice projection, he was cast as Mona Rudo's father Rudo Luhe for the 
promotional short film Wei Te-sheng made in 2003 and for the epic feature film he released in 2011. Pawan has no cultural or linguistic aspirations that I know of; he just wants to grow coffee on his hillside farm and run a café called Chez Rudo Luhe in Gluban.

Iwan Pering is the only translator with an academic background. She wrote a master's thesis about "village construction," which she treated in terms of "the revitalization (重振 chóngzhèn) of local knowledge and village culture" (Yiwan Beilin 2006: 154). The thesis is about her village, but she clearly has a wider purview, as I demonstrated above in my discussion of gaya and qduriq. Today she is trying to revitalize Seediq culture throughout central Taiwan by helping to run a Seediq-taught master's program at Providence University.

Finally, Watan Diro, the Toda translator, is a Presbyterian pastor who, though he is Toda, preaches in Tgdaya every Sunday in the church in Zhongyuan (Japanese: Nakahara), which is located up the road from Gluban.

Religion is another way of differentiating the translators: Watan and Dakis are Presbyterian, while Pawan and Iwan are Catholic. Though the churches take positions on social issues, age is a stronger predictor of attitudes. Iwan and Watan, now in their fifties, are more than a decade younger and socially more liberal than Dakis and Pawan. Iwan, who is contravening the traditional division of labor in allowing women to study hunting and men weaving in the program at Providence University, can be described as a feminist, and a Presbyterian service in Zhongyuan was the last place I expected to hear an appeal for open-mindedness about gay marriage. Such open-minded progressiveness is partly a function of geography, because Watan and Iwan, unlike Dakis and Pawan, have both lived abroad, in Ottawa and Honolulu respectively.

For all their differences, the translators are the same in some respects. They all speak Mandarin at least as well as they speak Seediq. Even so, they see themselves as capable of representing the contemporary relevance of the traditional culture to the Seediq community and to a wider audience. They must accept that they cannot know exactly what the traditional lifestyle was like, let alone live it. What they can do is reinterpret, to fit the fragments of what they know into some meaningful whole. Their reinterpretations of Seediq, in an ongoing adaptation to modernity, will naturally involve qduriq, better understood as a strategic "retreat" so as to regroup rather than as an ignominious "flight." The Seediq people will have to choose their battles wisely. But unlike Mona Rudo, who was, as Pihu Sapu puts it, "driven to bay by that policeman [Yoshimura] from the lumberyard" ( $S B$ 1:28:02), and unlike Hanaoka Ichirō, the "model savage" who advocates accommodation to modernity in the film, the translators have a choice: nobody has forced their hand; they can decide when, where, and how to take a stand.

They took a stand by choosing to participate in the translation of Seediq Bale despite the potential flak they might take from other elites in the Seediq community. While Iwan Pering is now very critical of the film, she did participate in the translation of the screenplay in September 2009. Eighty years before, the translators' Tgdaya and Toda grandparents had been at one another's throats, 


\section{Introduction}

literally. Now, instead of fighting it out, the translators were talking out their differences as they worked on a Seediq representation - their translation of Wei's screenplay into Seediq - of what happened on October 27, 1930, and why.

Now they were also participating in other collective projects. The year before taking up the translation of Seediq Bale, Dakis, Iwan, and Watan spearheaded a successful application for state recognition of the Seediq of Nantou County under the ethnonym Sediq (Guo 2008). They also worked on the compilation of a threedialect dictionary. Dakis and Watan are working on a Seediq translation of both testaments of the Bible. They are all engaged in a collective project of linguistic and cultural revitalization, which Watan tirelessly promotes under the slogan 3S3T: 3S for Seediq, Sediq, and Seejiq and 3T for Tgdaya, Toda, and Truku. They are all active, and they act together.

Therefore, rather than as authorities, let us regard Dakis, Pawan, Iwan, and Watan as activists who build consensus through interlingual translation in order to plant selected seeds of cultural "revitalization" for the sake of Seediq's survival. Survival in some form is what the Seediq are fighting for now and what Seediq Bale is all about.

\section{The relation between the data and my claims}

When I started studying the translation of Seediq Bale, a couple of contradictory claims had been made by a few scholars who had drawn on some of the evidence. The subtitles had been available for download since 2011, the DVDs for online order since 2012. Wei Te-sheng's screenplay (Wei 2000), on which the subtitles were based, was in the library. The comic on which the screenplay was based (Qiu 2011 [1990]) and Dakis Pawan's two books (Guo 2011, 2012) were in the convenience stores on practically every street corner in Taipei. Iwan Nawi's translation of the screenplay into the Toda dialect (Wei 2014) was in the bookstore. The contradictory claims scholars had made about this evidence were that on the one hand Wei misrepresented Seediq history and culture ( $\mathrm{Li}$ 2016; see ch. 6) and that on the other hand he "subtitled Seediq values" (Lee 2016). Li Yiqian's scholarship is admirable, but I think Elaine Lee was closer to the truth.

While I can hardly say I have all the relevant evidence, I have assembled more evidence than anyone else. I have looked at the Japanese sources of the screenplay, which were translated from Seediq and Japanese by colonial linguists and ethnographers and then from Seediq and Japanese to Mandarin by Shen Mingren, also known as Pawan Tanah. I have various versions of the "Seediq shooting script," which includes backtranslations of those same colonial sources.

To deal with the evidence, I have acquired reading knowledge of Seediq. On this basis, I can assert that critics like Li Yiqian (Li 2016) who claim that Wei Tesheng misrepresented Seediq culture are dependent on Seediq activists, especially Dakis Pawan. With all due respect to Dakis Pawan, the translational data does not always bear out claims that Seediq activists like him make, as I have already shown with regard to qduriq. 
When I pointed out to Dakis that táo was sometimes translated qduriq in the film, he was surprised. I will discuss many other examples that he might find surprising, on the principle that our understanding of Seediq culture depends on evidence to which everyone, including Dakis Pawan, is beholden. Claims people like Dakis Pawan make tell us about ausbau attempts to standardize tradition, but they have to be understood in the context of what is still a relatively abstand culture.

I may seem to be claiming I can represent Seediq culture better than Dakis Pawan, as if I am the cultural authority who makes claims on the basis of evidence and Dakis Pawan is merely the activist who says things he would like to be true. I should therefore stress that Dakis is like a soaring peak, while I am like a hill - as in the mound that ants make. The most I can hope, in all humility, is that, in digging around in the data, I have been empirical: that I have made some claims in an explicit framework that are plausible explanations of the evidence, explanations that Dakis might find interesting, but which are subject to revision, amenable to improvement.

I make specific claims about Wei Te-sheng's Mandarin-language screenplay and about the Seediq translation. With regard to the screenplay, I claim it is a decent approximation of Seediq culture, an achievement that we can understand historically. First, it drew on a Seediq song and story recorded during the Japanese colonial era. Second, it was produced in the two decades following the launch of the local indigenous movement by someone who supported and sympathized with the movement. Third, it was edited based on feedback from the Seediq translators.

With regard to the Seediq translation, I claim it is a work of art in its own right that contributes to the artistic achievement of the film and articulates an interpretation of the Musha Incident and of Seediq culture in Seediq terms, an interpretation that is modern. That the interpretation is modern is most obvious when the translation is a backtranslation. The way the song changed in translation and backtranslation from 1917 to 2009 can be explained with reference to the translators' indigenous modernity, which should also be understood historically: the translators grew up in modern Taiwan, but by participating in the same indigenous movement Wei Te-sheng supported and sympathized with, they have adapted their culture into an alternative modernity.

I have a general claim to make, too, about their approach to translation. If Iwan Pering is right, translating táo into qduriq in the context of the film is a foreignization (because the warriors in Seediq Bale only say qduriq as a result of culturally insensitive translation), tutuy a domestication (because tutuy is what a warrior would say, at least according to Iwan Pering). ${ }^{5}$ As I have shown, the translators ended up using both tutuy and qduriq. I will show that they domesticated and foreignized throughout the translation. I imagine that indigenous and minority translators in general demonstrate their adaptability by domesticating and foreignizing their ways to "fluencies" that are evolving compromises with texts from dominant cultures, and with the dominant cultures in which the texts were produced.

\section{Overview of the book}

In the preface, in order to prepare the reader for the interlinear line of analysis in my three-line presentation of linguistic data in the acknowledgments and 


\section{Introduction}

the pages on Seediq phonology, morphology, and syntax that follow, I explained interlinear analysis and why I was using it: as a foundation for the thick description of a case of indigenous cultural translation I am attempting in this book.

This introduction has been a mise-en-scène for the case. I introduced the Musha Incident, the dramatic anticolonial rebellion Seediq Bale is about, in relation to "indigenous modernity," which is a context for my study of the Seediq translation of the Mandarin screenplay.

Then I discussed the conditions in which this translation took place, by introducing the Seediq translators, particularly their disagreements about their still relatively abstand culture. A discussion of both the translators' disagreements and their collective activities was the basis of the claim that the Seediq translators are better regarded as consensus-minded activists trying to standardize and thereby revitalize their culture than as authorities trying to describe it. Then I suggested how the evidence I have excavated supports the claims I make, and I am ending with an overview. To keep the discussion as down to earth and close to the case as possible, I put my definitions of keywords in the endnotes below.

In chapter 1, I dig into the textual history of Wei Te-sheng's screenplay from 1996 to 2011 in the language in which it was written, Mandarin. I argue that, despite all the liberties Wei took to turn history into an epic film, his screenplay's presentation of Seediq historical agents' perspectives is culturally plausible, as are the disagreements between these agents. The Seediq characters in the film may share the same culture, but they do not see eye to eye. The disagreements in the film about the legitimacy of rebellion imply a dialectic ${ }^{6}$ between traditionalists and modernists that has been driving Seediq adaptation ${ }^{7}$ to/of modernity since before colonization.

Then I wonder, how Seediq can the screenplay possibly be when Wei Te-sheng wrote it in Mandarin? I answer this question in the core chapters of the book, arguing that overall the Mandarin screenplay is quite foreignized. However, my main focus in the core chapters is on the Seediq translation (see table I.2).

In chapter 2, I treat the process and product of the Seediq translation of the screenplay in 2009 and 2010, mainly in terms of word order but with some

Table I.2 Plan of the Core Chapters

\begin{tabular}{llll}
\hline Ch. & Title & Mode & Level \\
\hline 2 & $\begin{array}{l}\text { Refining the ore: } \\
\text { From foreignization and domestication to fluency }\end{array}$ & Translation & Text \\
& $\begin{array}{l}\text { The game of telephone: } \\
\text { Cultural translation as adaptation }\end{array}$ & Backtranslation & Text \\
4 & $\begin{array}{l}\text { Pacifying the pine: } \\
\text { How to demilitarize headhunting songs }\end{array}$ & Backtranslation & Text \\
6 & $\begin{array}{l}\text { The dialectic of } d \text { mahun: } \\
\text { The thicker backtranslation of cultural keywords }\end{array}$ & Backtranslation & Term \\
7 & $\begin{array}{l}\text { From Hako Utux to Rainbow Bridge: } \\
\text { Into the translational middle ground }\end{array}$ & Backtranslation & Term \\
& Adapting terminologically & Translation & Term \\
\hline
\end{tabular}


attention to word choice. In response to an assumption in minority translation studies that translators would, on the basis of their strong identities, tend to domesticate into the minority language in order to protect it, I show how the Seediq translators did it all, foreignizing and domesticating their way from a stiff literalism to a "fluent" idiom that takes full advantage of Seediq's sonic features.

Chapters 3 and 4 form a pair in which I discuss the translation and backtranslation of texts. In chapter 3, I discuss two cases where texts, one a 200-word story and the other a single line, were translated from Seediq into Japanese during the 1930s, into Mandarin in the 1990s, and back into Seediq in the 2000s. I discuss these cases as spaces for flights of imagination by indigenous translators that matter to Seediq identity today and which exemplify the creativity that has driven the Seediq adaptation to modernity. In chapter 4, I take the same approach to a Seediq headhunting song that can be sourced to the 1910s, arguing that prosody both constrains translators and liberates them by giving them another reason for rewriting.

Chapters 5 and 6 form another pair in which I discuss the translation and backtranslation of terms. (Note that I use "term" in the far-right column of table I.2 to include both words and phrases; I will discuss terms in the sense of terminology in chapter 7.) In chapter 5, I argue that the Seediq translators articulated their own Seediq interpretation of the Musha Incident in their translation, which is also an interpretation of Seediq culture as it has evolved since 1930. Their translation is a "thicker backtranslation" of Mandarin translations of key Seediq concepts. It is thicker not only because the translators restored the terms to their original linguistic context, but also because that context had changed drastically since 1930. Having found Wei's Mandarin translations of Seediq keywords to be relatively foreignized in chapter 5, I go on in chapter 6 to discuss the translation of the wider web of traditional terms in terms of a translational "middle ground."

A leitmotif in chapters 3 to 6 is the modern reinterpretation of "myths" traditional stories that provide guidance - and meanings as the Seediq people brew new wines to put in old bottles, new cultural meanings to express with preexisting Seediq texts and terms. In chapter 7, I serve a selection of wines that are distinctly modern: I complement the study of traditional vocabulary in chapter 6 with an anatomy of modern terminology. In anatomizing the modern Seediq lexicon in chapter 7, I show how loanwords, which are foreignizations, complement native adaptations, which might be termed domestications. I suggest that the complementarity of the modern Seediq lexicon should characterize any culture's adaptation to modernity.

In the conclusion, I recapitulate the argument that the interlingual translation of Seediq Bale was informed by a "translation" of Seediq culture into an alternative modernity. I go on to speculate upon what kind of alternative it is. I then make a home for my approach, indigenous cultural translation, in translation studies and recommend my method, the thick description of translation, for the study of cases of indigenous translation around the world. 


\section{Introduction}

\section{Notes: seven keywords}

1 Indigeneity in Taiwan: About 6,000 years ago, headhunter-planters arrived in Taiwan, probably from coastal China. About 1,000 years later, some of the new arrivals sailed south. If the "out of Taiwan" hypothesis (Diamond 2000: 709) of Austronesian ("south island") cultural dispersal is correct, ancestors of the Maori and the Malagasy once lived in Taiwan. The headhunter-planters who stayed in Taiwan, and who are retroactively Austronesian, diversified for three reasons besides cultural drift: interaction with even more aboriginal hunter-gatherers, adaptation to new environments, and a drive to be different. The first culturally Chinese settlers arrived in the 17th century. From 1683 on, the coastal plains were ruled by the Qing. The Seediq first appeared in 18th-century historical records. But by 1895 the Seediq were still stateless, living beyond the "pale" in the mountains. The Taiwanese "pale" was the 蕃界 fänjiè, literally the "hedge boundary" (Teng 1996: 43), a line that settlers were not allowed to cross. The fān in fänjie became the word for the "savages" who lived beyond that line. The Japanese were the first colonizers to conquer the mountains, but they kept the "indigenous territory" separate from the plains. They governed through chiefs until 1930, thereafter through more trustworthy intermediaries. During the war the population was "imperialized," and after the war it was Sinified by the Kuomintang. By the 1980 s, there was overt resistance to Kuomintang rule, including indigenous resistance.

The indigenous resistance radicalized after the lifting of martial law in 1987, as a "belated" local current within "international indigenism," which is usually dated to the 1960s (Simon 2016). There were calls in Taiwan for the return of indigenous sovereignty (see chs. 1 and 4). The state responded with multiculturalism and recognition. In 1994, the state recognized indigenous people, in 1996 indigenous peoples (Shih 1999). At the time the Seediq were lumped with the Atayal, but there was now a legal mechanism for further recognition. According to Dakis Pawan (Guo 2008), the Truku who migrated to the east coast in precolonial times are Seediq, but many east coast Truku disagree, and the Chen Shuibian administration sided with the east coast Truku. The east coast Truku nation was recognized in 2004, the "Sediq" nation of central Taiwan in 2008. In addition to geographical divisions, there are also social cleavages between ordinary people and competing elites who try to promote their understandings of indigeneity to advance their interests (Rudolph 2008; cf. Simon 2016). My own observation is that elites also cooperate, partly to try to advance ordinary people's interests.

Terminologically, the government uses the term "tribe" to refer both to village communities like Gluban and to imagined communities like Sediq. I avoid "tribe," which is pseudo-technical and exoticizing, in favor of "community." The Mandarin term 原住民 yuánzhùmín could be translated "aboriginal," but I use "indigenous" in support of "activists eager to shift the focus from primordialism to human rights" (Friedman 2018: 80 note 1). "Indigenous" stresses the Seediq right to self-definition. However, the Seediq had to get approval as a condition of recognition, so that Seediq self-definition is the product of state-society interaction, at any scale. Referring to community-building programs designed to counteract social alienation, Kerim Friedman claims that "the contemporary identification of Taiwanese indigenous people with their [village communities] . . . must itself be understood as a product of the nationstate and its promotion of a particular kind of local authenticity" (2018: 95).

I use some related terminology: Han means ancestrally from China. Chinese covers cultural and linguistic elements that are common to Mandarin, Taiwanese, and other Chinese languages. Taiwanese means either from Taiwan or Southern Hokkien as a culture or a language. I mostly avoid the term native because indigenous people share Taiwan with other people who were born there ("native" is from naitre, "to be born" in French): descendants of Southern Hokkien and Hakka settlers and of refugees of the Chinese Civil War. While an individual can identify in a certain way, ancestrally everyone is mixed; Taiwan's history is a tale of "Interethnic Weddings" (Ye 1994). 
To the People's Republic of China (PRC), Taiwan's indigenous peoples have been a single "national minority," the Gaoshanzu, the "High Mountain Tribe" - a designation that apparently leaves out populous coastal peoples like the Amis - since 1954. But the PRC can hardly define the meaning of indigenous or decide its application by fiat. If it could, one could hardly discuss "indigeneity" in China (Hathaway 2010).

2 Tradition/modernity: Tradition refers to the gradually evolving precolonial Seediq lifestyle, modernity to the rapidly evolving colonial Seediq lifestyle. I use the tradition/modernity binary for three reasons: first, while tradition is an attempt to rein in change at any time, modernity implies recent history and therefore certain kinds of inculcated self-control and types of technology, which has enabled us to construct concrete jungles to live in and screen-based media to get lost in. Second, tradition and modernity are terms the Seediq translators themselves use: tradition is 傳統 chuántŏng gaya rudan, modernity 現代性 xiàndàixìng gaya hndure. Third, although tradition/modernity has been used to do violence to indigenous people, it is not blood-drenched like savagery/civilization, the binary the film deconstructs: Mona Rudo sees himself as civilized (see ch. 5 pp. 105-106), and the Japanese are savage (see ch. 1 p. 36).

The tradition/modernity binary should also be deconstructed. Mona Rudo's village submitted in 1907, but villagers had been trading produce for money, weapons, or salt for decades (see ch. 7). To some extent, the Seediq have self-modernized. One way they have modernized is by standardizing and revitalizing their tradition. Any binary is vulnerable to deconstruction, but to deconstruct is not to demolish. Used dialectically (see note 6), this binary is a way of approaching Seediq cultural adaptation (see note 7).

Though screen-based mediation is arguably part of postmodernity, I use the term modernity inclusively. I see modernity as an unfinished project (Habermas 1996 [1980]), where the interplay between modernities and traditions produces alternatives (Gaonkar 2001).

3 Empiricism: One way that Dakis Pawan is modern is that he is empirical (see Larsen 1987), though of course not every modern person embraces empiricism (for those in translation studies, see Pym 2016). Empiricism is an evidence-based dialectical approach to the description of reality. Classical mechanics mostly fits the evidence, but relativistic mechanics complements it without cancelling it out. The findings of minority translation studies are true as far as it goes, but the evidence does not justify the anxiety over foreignization or the recommendation for its avoidance (see ch. 2). Li Yiqian's scholarship is excellent and her conclusions solid, but I can draw on additional evidence to better describe the significance of the translation (see ch. 6). Otherwise, I am out on my own, in uncharted territory, and a contextualized understanding of the evidence can be my only guide.

4 Abstand/Ausbau: An abstand language, literally a language by distance, is a dialect chain, while an ausbau language, a language by development or design, is standardized (Kloss 1967). Without top-down pressure to conform, an unstandardized language can contain astonishing variation, which is a function not just of geography but also of local identity. A standardized language is never uniform, because people always try to stand out in their language use. Abstand languages are typically spoken by small communities, ausbau by large. Heinz Kloss claimed that in modern times 50,000 speakers is a minimum number for a viable language community (1977, cited in Mühlhäusler 1996: 264), but actually fifty is enough, if young people insist on speaking their ancestral tongue. The standardization imposed through the monolingual national language policy in Taiwan, which was only replaced with official multilingualism in the 1990s, is part of why Seediq is endangered; it is unclear if the standardization of Seediq will facilitate its revitalization, but that is the rationale. Abstand/ausbau applies to culture, too, but when culture is standardized, people may not conform, and even if a country is officially multicultural, people may not want to be pigeonholed. 
5 Domestication/Foreignization: Domestication and foreignization are Lawrence Venuti's translations (1995: 19-20) of Friedrich Schleiermacher's terms (verdeutschend and verfremdend) for two approaches to translation (2012 [1813]). I do not use Venuti's translations exactly according to Schleiermacher's understanding of the approaches or ascribe the same values to them as Schleiermacher or Venuti.

For Schleiermacher, a translator either "moves the reader toward" (Schleiermacher 2012 [1813]: 49) the writer (foreignization) or the writer toward the reader (domestication). While I accept the salience of authorial (or "writerly") intention, I also use domestication and foreignization in terms of approaches to the foreign text and its context. While Schleiermacher is either/or (49), as if a translator can either foreignize or domesticate, never both, I assume most translations, at the term level and text level, are in a "middle ground" (see ch. 6 sec. 1) between the writer and the reader, the original culture and the target culture. After all, Schleiermacher uses the preposition toward (in Susan Bernofsky's translation), not to. Schleiermacher preferred foreignization as a way of expanding the expressive capacity of the language he spoke, German, Venuti valorizes foreignization into English as a way of disrupting its dominance, while I assume that foreignization and domestication are both legitimate ways of developing a vulnerable language.

6 Dialectic: A dialectical perspective on cultural change models it as a "gradual" (in the etymological sense of "stepwise") evolution of ways of understanding, speaking, and acting as temporary resolutions to conflicts between traditionalists and modernists (see note 2). Traditionalist and modernist are roles the same person might play in different contexts. Traditionalists resist modernists, slowing but not stopping linguistic and cultural change by appealing to "tradition," a codification of adaptation (see note 7). As a translator, I focus on innovations introduced through translation, but many innovations are internal. As Tord Larsen puts it: "The freedom which goes into the construction of cultural meanings also provides a way out of them; any culture contains within itself the seeds of its own destruction, the very same seeds it uses to produce and reproduce itself" (1987: 21). A similar point applies to language use. Friedrich Schleiermacher put it this way in his seminal talk on translation: though "bound" by language, every "free-thinking, intellectually independent individual shapes the language in his turn" (2012 [1813]: 46).

7 Adaptation: Evolutionary, cultural, and intermedial "adaptation" seem related. All three senses of the word refer to processes and products. Evolutionary adaptation as a process has bequeathed each of us a set of adaptations, a skill set by virtue of which colonized indigenous peoples can adapt themselves to colonial modernity and directors can adapt written texts into films. The common thread is systemic experimentation, of trying new things and seeing what works in the context of the system, which might contain subsystems and be embedded in a larger system. Not everything works: many experiments fail; all adaptations might be maladaptations in a slightly different system. But we can nonetheless make do and even thrive, as a species, as peoples, or as individuals, because of or in spite of history. This is obviously not to say that cultural and intermedial adaptation can be reduced to evolutionary adaptation. Evolutionary adaptation is slow, blind, and passive, while cultural adaptation and intermedial adaptation are fast, self-reflexive, and choice-based. Nor is intermedial adaptation reducible to cultural adaptation: cultural adaptation is the popularization of individual adaptations; intermedial adaptation is the remediation of texts in specific cultural contexts.

For my purposes, culture as adaptation is a complement to, or a context for, culture as identity: culture is part of what makes groups distinctive, to be sure, but we can also regard a culture as a suite of ways of doing things and an experimental process of finding ways of doing things better. If we consider a culture in this way, we might even feel that we have something to learn from, for instance, the Seediq. 


\section{References}

Barclay, Paul D. (2017) Outcasts of Empire: Japan's Rule on Taiwan's “Savage Border," 1874-1945, Oakland: University of California Press.

Bawan Danaha (Pawan Tanah; Shen Mingren) (1998) Chongxin Zuling de Minzu: Saideke Ren (The People Who Worship Ancestral Spirits: The Seediq), Taibei: Haiweng.

Chen Shujuan (Chen Shu-Chuan) (2010) "Taiyayu de Yuyan Huoli yu Yuyan Fuzhen - Yi Simakusi ji Zhudong Wei Li" (Language Vitality and Language Revitalization of the Atayal in Taiwan: The Cases of Smangus and Chutung), Taiwan Yuwen Yanjiu (Journal of Taiwanese Languages and Literature), 5.1 (March): 15-36.

Deng Xiangyang (2000) Fengzhong Feiying: Wushe Shijian Zhenxiang ji Huagang Chuzi de Gushi (Dana Sakura/Cherry Blossoms in the Wind: The Truth of the Musha Incident and the Story of Hanaoka Hatsuko [Obing Tado]), Taibei: Yushan.

Diamond, Jared M. (2000) "Linguistics: Taiwan's Gift to the World," Nature, 403: 709-710.

Friedman, P. Kerim (2018) "The Hegemony of the Local: Taiwanese Multiculturalism and Indigenous Identity Politics," Boundary 2, 45.3: 79-105.

Fubu Bingcilang (Hattori Heijirō) (2002 [1931]) "Guanyu Wushe Shijian" (About the Musha Incident), in Dai Guohui (ed); Wei Tingchao (trans), Taiwan Wushe Fengqi Shijian: Yanjiu yu Ziliao (The Uprising at Musha, Taiwan: Research and Materials), Taibei xian, Xindian shi: Guoshiguan (Academia Historica), 733-767.

Gaonkar, Dilip Parameshwar (ed) (2001) Alternative Modernities, Durham and London: Duke University Press.

Guo Mingzheng (Dakis Pawan) (ed) (2008) Saideke Zhengming Yundong (Seediq Name Rectification Movement), Hualian: Guoli Donghua Daxue Yuanzhumin Minzu Xueyuan (College of Indigenous Studies, National Dong Hwa University).

Guo Mingzheng (Dakis Pawan) (2011) Zhenxiang Balai: Saideke Balai de Lishi Zhenxiang yu Suipai Zhaji (Truth Bale: The Historical Truth of Seediq Bale and a Production Diary), Taibei: Yuanliu.

Guo Mingzheng (Dakis Pawan) (2012) You Jian Zhenxiang: Saidekezu yu Wushe Shijian (Seeing the Truth Again: The Seediq People and the Musha Incident), Taibei: Yuanliu.

Habermas, Jurgen (1996 [1980]) "Modernity: An Unfinished Project," in Craig Calhoun et al. (eds), Contemporary Sociological Theory, Chichester, West Sussex: WileyBlackwell, 444-450.

Hathaway, Michael (2010) "The Emergence of Indigeneity: Public Intellectuals and an Indigenous Space in Southwest China," Cultural Anthropology, 25.2: 301-333.

Hattori Heijirō (1981 [1931]) "Musha Jiken Nitsuite" (Concerning the Musha Incident), in Tai Kokuki (Dai Guohui) (ed), Taiwan Musha Hōkijiken: Kenkyū to shiryō (The Uprising at Musha, Taiwan: Research and Materials), Tōkyō: Shakai Shisōsha, 535-561.

Keesing, Roger M. (1985) "Conventional Metaphors and Anthropological Metaphysics: The Problematic of Cultural Translation," Journal of Anthropological Research, 41.2 (July): 201-217.

Kloss, Heinz (1967) “Abstand Languages and Ausbau Languages," Anthropological Linguistics, 9.7 (October): 29-41.

Kloss, Heinz (1977) "Ten Types of Language Planning," in B. P. Sibayan and A. Gonzales (eds), Language Planning and the Building of a National Language, Manila: Linguistic Society of the Philippines. 


\section{Introduction}

Larsen, Tord (1987) “Action, Morality, and Cultural Translation," Journal of Anthropological Research, 43.1 (June): 1-28.

Lee, Tzu-yi Elaine (2016) "The Subtitling of Indigenous Values in the Film Seediq Bale," Other Modernities, Special Issue (February): 58-67.

Li Yiqian (Lee Yi-chien) (2016) "Duochong Xunhua yu Yuhui Zhengming: Saideke Balai Zimu Fanyi zhong de Yiyi Liuzhuan" (Multiple Domestications and Indirect Rectification: Semiotic Shifts in the Subtitle Translation of Seediq Bale), Taiwan Wenxue Yanjiu Xuebao (Journal of Taiwan Literary Research), 23: 39-68.

Mühlhäusler, Peter (1996) Linguistic Ecology: Language Change and Linguistic Imperialism in the Pacific Region, London: Routledge.

Niezen, Roland (2003) The Origins of Indigenism: Human Rights and the Politics of Identity, Berkeley: University of California Press.

Pacidal, Nakao Eki (2012) "Zhongjianzhe zhi Lian: Saideke Balai de Yuanzhumin Lishi Yanjiuzhe Yingxiang" (The Face of the Inbetweener: The Image of [the] Indigenous History Researcher as Reflected in Seediq Bale), Taida Wenshizhe Xuebao (Humanitas Taiwanica), 77 (November): 167-197.

Pym, Anthony (2016) "A Spirited Defense of a Certain Empiricism in Translation Studies (and in Anything Else Concerning the Study of Cultures)," Translation Spaces, 5.2: 289-313.

Qiu Ruolong (2011 [1990]) Manhua Balai: Taiwan di yi bu Wushe Shijian Lishi Manhua (Comic Bale: The First Historical Comic of the Musha Incident), Taibei: Yuanliu.

Rudolph, Michael (2008) Ritual Performances as Authenticating Practices: Cultural Representations of Taiwan's Aborigines in Times of Political Change, Berlin: LIT Verlag.

Schleiermacher, Friedrich; Susan Bernofsky (trans) (2012 [1813]) "On the Different Methods of Translating," in Lawrence Venuti (ed), The Translation Studies Reader, 3rd edition, London and New York: Routledge, 43-63.

Scott, James C. (2009) The Art of Not Being Governed: An Anarchist History of Upland Southeast Asia, New Haven: Yale University Press.

Shih Cheng-feng (1999) "Legal Status of the Indigenous Peoples in Taiwan," www. taiwanfirstnations.org/legal.html.

Simon, Scott E. (2015) "Making Natives: Japan and the Creation of Indigenous Formosa," in Andrew D. Morris (ed), Japanese Taiwan: Colonial Rule and Its Contested Legacy, London: Bloomsbury Academic.

Simon, Scott E. (2016) "From the Village to the United Nations and Back Again: Aboriginal Taiwan and International Indigenism," Taiwan Journal of Indigenous Studies, 9.3 (Fall): 49-89.

Teng, Emma J. (1996) Taiwan's Imagined Geography: Chinese Colonial Travel Writing and Pictures, 1683-1895, Cambridge: Harvard University Asia Center.

Venuti, Lawrence (1995) The Translator's Invisibility: A History of Translation, New York and London: Routledge.

Wei Desheng (Wei Te-sheng) (2000) Saideke Balai (Seediq Bale), Taibei: Xinwenju (Government Information Office).

Wei Desheng (Wei Te-sheng) (2011) Daoyan Balai: Teyouzhong Wei Desheng de Saideke Balai shouji (Director Bale: Endemic Species/Particularly Spunky Wei Te-sheng's Seediq Bale Diary), Taibei: Yuanliu. 
Wei Desheng (Wei Te-sheng); Yiwan Nawei (Iwan Nawi) (trans) (2014) Kari Toda Patas eyga Sediq balay (The Toda Language Screenplay for Seediq Bale)/Saideke Balai Saidekeyu Jubenshu (Seediq-Language Screenplay for Seediq Bale), Taibei: Yushan.

Ye Shitao (1994) Yizu de Hunli (Interethnic Weddings), Taibei: Huangguan.

Yiwan Beilin (Iwan Pering) (2006) "Utux, Kongjian, Jiyi yu Buluo Jiangou: Yi Alang Tongan yu Alang Sipo wei zhu de Taolun" (Spirits, Space, Memory, and Village Community Construction: Discussion Mainly of Tongan and Sipo), Master's thesis, Guoli Donghua Daxue (National Dong Hwa University). 


\section{References}

1 The population of the six rebellious Tgdaya villages before the attack was 1,236 . Only 298 of these people survived the Japanese reprisal and the Second Musha Incident.

2 Wei Te-sheng plans to start shooting his Tainan trilogy in 2020: see http://zeelandia. com.tw/. The fact that Wei Te-sheng grew up in Tainan helps explain his heroic nationalism, his religion, and his primitivism, which, I claim, are approaches to the problem of alienation. Wei grew up within walking distance of the places where the Dutch first came ashore in 1624, where the Dutch were ousted by Koxinga in 1661, and where Koxinga's grandson was ousted by Shi Lang, a Qing dynasty admiral, in 1683. Tainan has had a pocket of Presbyterianism since the Dutch era that has for the past five decades supported Taiwanese nationalism and demanded democracy (Stainton 2000: xi). Tainan Presbyterianism is part of Wei's concern for indigenous peoples, whom the church has championed. Finally, residents of southern cities like Tainan tend to feel that industrial modernity has been imposed on them by the Chinese regime that ruled from the north.

3 In its recent English translation by Michael Berry under the title The Remains of Life (Wu 2017 [1999]), the novel was a finalist for the Best Translated Book Award.

4 There are a number of "diegetic" historical documents in the film:

SF 5:31 The 1895 transfer of Taiwan (as per Shimonoseki Art. 2 (b) \& Art. 5.2)

$S F$ 6:48 Anachronistic use of an 1896 map (Campbell 1896: 398)

SF 37:21 The sign for the 1907 submission ceremony for Mhebu Village

$S F$ 1:58:44 The schedule for the sports day on October 27, 1930

$R B$ 3:09 A piece of calligraphy that blames the attack on excessive corvée

$R B$ 1:39:49 The leaflet calling on the Seediq to surrender

"Non-diegetic" titles include:

$S F$ 5:31 The text of the transfer of Taiwan's sovereignty

$R B$ 3:42 The text of the calligraphy, which was supposedly by the Hanaokas

$R B$ 1:39:50 The text of the surrender leaflet

$R B$ 1:58:24 Kojima Genji's role in the Second Musha Incident in April 1931

$R B$ 1:58:46 The march by the survivors to Kawanakajima in May 1931

$R B$ 1:59:20 The history of Mona's remains from recovery in 1934 to reburial in 1974

5 Wei bent historical fact in other ways to turn Mona into an epic hero. Born in 1880 or 1882, Mona would have been fifteen at the oldest in the prelude that opens the film, too young for a headhunt. In the film Mona as a young man was played by an actor who was thirty-two during production! In real life, Mona was nowhere near Renzhiguan or Jiemeiyuan in 1902 or 1903 (see table 1.1), but he is at both incidents in the film as a way of keeping him in the spotlight.

6 The only problem with the brilliant trope of Mona saving up powder from matchheads for years in preparation for rebellion is that matchhead powder is formulated not to explode.

7 Pastor Kumu Tapas is a modern-day critical Seediq woman. She is particularly critical of Mona Rudo in the extensive collection (2004) of Seediq texts with Mandarin translations she published about the Musha Incident. To my Tgdaya Seediq friends, Kumu is biased against Mona, probably because she is a Toda woman. But this is a story for another day.

8 Most Seediq people today can accept the state's monopoly on the legitimate use of violence against human beings, if its use is actually legitimate; but many cannot accept certain restrictions upon what they see as their own legitimate use of violence against animals. See Simon and Tsai 2015 for a nuanced discussion of the contemporary fight for hunting rights in relation to conservation. 
$1 \mathrm{SVO}$ is often described as a basic "word" order, but strictly speaking it combines two levels, lexical and syntactic. While a V(erb) is a word, a S(ubject) is a phrase, as is an (O)bject.

2 The adverb of degree yidiăn normally follows the verb. This is one of many exceptions to the AV (Adverb-Verb) norm in Mandarin.

3 It turns out that "fluent" and "flow" are not cognate, but derive from different Proto-IndoEuropean roots.

4 Hanaoka Ichirō in real life had also visited Japan (Asai 1953: 80-84).

5 In subsequent chapters I will refer to Dakis when I discuss the Tgdaya translation, partly to avoid having to repeat "and his colleagues" each time, partly because Dakis spent a month on the draft of the Seediq shooting script and over six months on set. His colleagues Pawan Nawi and Iwan Pering contributed to the final result, but if one had to pick a single person who was responsible for that result, it would be Dakis. The Tgdaya translation is Dakis's in the way that the film is Wei Te-sheng's.

6 In discussing translator strategies, I draw on Roman Jakobson's distinction between metaphor and metonym in his article on aphasia (Jakobson and Halle 1971 [1956]). Jakobson's metaphor and metonym form a pair of translation strategies. They are the twin hemispheres in a translator's competence. For instance, the translation of zhìdào, more or less "know," into m-kela, the agent focus form of kela, which is also roughly "know," is metaphorical, because it is based on semantic similarity. Also for instance, the translation of a Mandarin phrase that means roughly "how formidable the Japanese are" into a Seediq phrase that means roughly "the Japanese will not be overcome by us" is metonymic, because it is based on contiguity: being formidable is a quality that inheres "in" the Japanese (so it is technically a synecdoche, which is also defined in terms of contiguity), and all the potential effects of this quality, like that the Japanese are unbeatable, are temporally contiguous with the quality. Metaphor and metonymy do not just apply to translation at the clause level, they also apply at the word level, as I will show in the conclusion to chapter 7.

I should note Maria Tymoczko's use of the concept of metonymy in her study (1999) of translation in postcolonial Ireland. According to Tymoczko, the selection of Irish texts to translate into English was metonymic, because the translated texts were only parts of the tradition but represented the whole tradition for English readers and Irish nationalists alike. Following Tymoczko's lead, I could describe the standardization of Seediq culture (see the introduction sec. 2 and ch. 6 sec. 1) as a metonymic or "synecdochal" process.

7 The terms I use in my prosodic analyses describe Seediq prosody as well as they describe English, even though they were developed to describe the quantitative meters of Greek and Latin. Prosodic patterns like choriamb - BA ba ba BA - obviously translate: a choriamb is LONG-short-short-LONG in Greek or Latin, STRESSED-unstressed-unstressedSTRESSED in English or Seediq.

1 Visit the eResources at www.routledge.com/9780367198558 for the audio and text to Rudo Luhe's monologue.

2 Shell garments are part of Atayalic material culture. The term lukus kerang in Seediq corresponds to lukus qaxa' in Atayal: see http://catalog.digitalarchives.tw/item/00/25/ a $8 / 10$ html. Both men and women wore shell garments. In an Atayal village surveyed in 1915, a man was expected to give a woman fifty to one hundred "shell skirts" as an engagement gift (Guan 2016: 66).

Note the similarity of karang, kerang, and kurang. The connection between karang, crab, and kerang, meaning "shell," is obvious. The resemblance between kerang and kurang, callus, is probably accidental, but it is memnonically useful: a kurang (callus) is like a kurang (shell) on the skin.

1 Arthur Holmer points out that rimuy co-occurs with maku in songs, strongly suggesting rimuy-maku is a word. His suggestion for the translation is "I really did get there, wow, halleluyah, really, look, look, look!" 
2 It was Principal Lituk Teymu who informed me that the location focus form of the verb for "grab" in Truku is spelled djiyan.

3 Hanaoka Ichiro got married on October 27, 1929, a year to the day before the attack. In a Facebook post, Professor Scott Simon explains why October 27 was such a special day. It was a day to commemorate Prince Kitashirakawa Yoshihisa's death during the conquest of Taiwan in 1895.

4 According to ethnobotanist Kevan Berg (by email), the trees Tado et al. are cutting down in the film are bald cypresses (Taiwania cryptomerioides) or perhaps Cunninghamias (Cunninghamia lanceolate). According to Paul Barclay, Yoshimura Katsumi was in Mhebu to supervise the felling of "gigantic cedars" (Barclay 2017: 49), while according to Deng Xiangyang, 檜木 kuàimù, a kind of cypress (probably Chamaecyparis formosensis), were logged in the hills above Mhebu (Deng 1998: 62).

5 One reason for periodic resettlement was land exhaustion due to swidden agriculture. Another was resistance to "the political coercion of would-be leaders" (Simon 2012: 164). The resettlement option was no longer available under the Japanese, which put hierarchical pressure on egalitarian communities.

6 In the introduction to this chapter, I suggested that the harung is now a symbol of cultural renewal, but added a "perhaps." I added the "perhaps" because the life cycle of the harung has not changed. The harung still relies on fires that annihilate the seeds of other trees to reproduce. In this light, the harung would be a symbol of the survival of one culture at the expense of another. Yet the ecology is not that simple. Pioneer species like the harung have to "yield the stage to more accommodating (陰 yin) secondary tree species" (Jiang 2007: 71). In yielding the stage, the harung is part of a process of "forest succession" that eventually produces mixed forests. Surely mixed forests could symbolize territorial sharing.

As to whether Seediq people today would still want to identify with a species of tree, I don't see why not. As I noted in endnote 7 to the introduction, the identity of a species is not fixed, but it is rather the product of evolutionary adaptation. Keeping in mind that compared with evolutionary adaptation, cultural adaptation is fast, self-reflexive, and choice-based; the harung could still be a symbol of Seediq adaptability and therefore of cultural renewal.

1 I use the word interpretation in the singular because I am offering a single multifaceted interpretation of the translation. Ideally, my interpretation of the translation would also find agreement among the translators. As I demonstrated in the introduction (p. 12), they are consensus-minded, despite their disagreements. It is in the spirit of consensus that I offer my interpretation, knowing that it is in the nature of things for any consensus to get revised.

2 The line about Nasuno being Pihu Walis's friend is the only allusion in the film to the Salamao Incident, as it is called today, in which Mona Rudo probably collaborated with the Japanese, helping them put down resistance among the Slamaw Atayal. According to Yan Yunnong's novelization (2011 [2004]: 205) of Wei's screenplay (Wei 2000), Pihu Walis and Nasuno were brothers in arms in the pacification of the Slamaw in 1920 .

3 The stone that the Seediq once buried is reminiscent of the hatchet that American Indians buried, in that the stone might simply represent the antagonism that both sides wanted to put behind them. There is another possibility. Given that according to Deng Xiangyang (2000: 123), the two parties to a Seediq peace-seeking ceremony would use a ladle to drip water on the stone before burying it, the stone might also be a symbolic seed out of which something new might grow.

4 According to Koizumi Magane, a Japanese ethnographer who visited the Wushe area in the late 1920s, when someone joined a community, he had to slaughter a pig to dmahunto "feast" - the members of the community, as a contribution to the community 
(Xiaoquan 2014 [1933]: 158-159). It appears that the same kind of contribution was part of the coming-of-age ceremony, at least for men.

5 There is at least one more way to understand the film's interpretation of the Wushe Incident in terms of dmahun. According to Iwan Pering (Wang and Yiwan 2012: 32), dmahun is a ritual of ablution, the goal of which is smino gaya. Smino is a verb in agent focus derived from the noun sino, wine. Though sino means wine, smino usually means "wash with water." In dmahun, however, blood is used instead of water. Smino gaya means "wash gaya in blood." What does this mean? According to Iwan, gaya here means "a state of pollution" that people wash away with blood. But according to her Toda informant, "blood is used to wash away those bad things, to wash the waya [Tgdaya: gaya] that we have damaged, and let it return to its original state." As a result, there are two ways to understand the Wushe Incident as a ritual ablution. The rebels were using blood either to wash gaya clean or to wash away a state of pollution. Mona Rudo seems to refer to a state of pollution that has to be washed away when he exhorts the warriors to:

$\begin{array}{llll}\text { 用 } & \text { 鮮血 } & \text { 洗淨 } & \text { 靈魂 ! }(S F \text { 1:56:04) } \\ \text { Yòng } & x \bar{l} \text { an-xie } & x \grave{l} \text {-jing } & \text { linghún! } \\ \text { use fresh-blood } & \text { wash-clean } & \text { soul } \\ \text { Use fresh blood to wash your souls clean! }\end{array}$

But Dakis Pawan did not use smino in his translation of this line or any other line in the screenplay. So while Wei Te-sheng interpreted the incident partly as a ritual of ablution, the translators did not, at least not in their translation.

\section{References}

1 正名 zhèngming, to "rectify names," is from the Analects. Confucius's "names" (ming) are social roles to which people should conform: fathers should behave like fathers should, for instance. This would be to rectify people, but as a result of how Confucius actually put it, and due to the fact that today ming includes both proper and common nouns, zhèngming is also taken to mean accurate description: words should match reality. What does this mean for translation? According to Li Yiqian, it means that domesticated translations should be rectified to foreignized translations that best match the reality of the original.

2 Citing classic studies by Vicente Rafael (1988) and Tejaswini Niranjana (1992), Douglas Robinson (1997) discusses how cultural compromises might be reached in a postcolonial "middle ground," a space in which creative writers, including translators, in former colonies like the Philippines and India might create a new language that is "in between" the language of the colonizer and the local language (102). In the future I hope to look into whether Seediq creative writers, including translators, have created an in-between language - perhaps a Mandarinized Seediq or a Seediqized Mandarin.

3 In Toda, the Pusu Qhuni is called the Rmdax Tasil, literally "shining stone." Rmdax Tasil is spelled Rmdaxtasing in Track 1 of the 2005 album Seediq Bale by the Taiwanese black metal band ChthoniC (Berry 2008: 95-99).

4 Historian Zhou Wanyao notes (2011: 5) that, unlike in the Chinese myth of Hou Yi, the archer who shot the sun on his own, the Seediq story of heroism is intergenerational.

5 On the translation of kinship terms, see Abraham Rosman and Paula G. Rubel (2003). The Austronesian language Kiriwina uses the word tama for "father," just like Seediq, but unlike Seediq, Kiriwina sorts kinship relations according to alienability. There is one genitive pronoun for inalienable relations like father and another for alienable relations like husband (Rosman and Rubel 2003: 273).

6 Mahung had a son and a daughter; both died during the reprisal (Jian et al. 2002: 354). 
7 Seediq names may be features of the natural environment. For instance, Baso is named after baso, proso millet (Zuoshan 2011: 1. 24). But the origins of most names are obscure.

8 In the 2000 screenplay, Wei transliterated Rudo Luhe's nickname Bàiyī. According to Dakis Pawan, Rudo Luhe was nicknamed Bae in an intentional mispronunciation of bare in awi bare, meaning "wasp" (Guo 2011: 92).

9 Alang, "village," comes from qalang, "fence." Thanks to Teymu (Kevin Bätscher) for pointing out the same metonymic connection between "town" and the German word Zaun, "fence."

10 Thanks to Li Yiqian for the reminder that both bùluò and -shè are colonial terms.

11 It is interesting to compare what Sayama Yükichi understood with what Dakis Pawan, the consultant on the Mandarin translation of his book, thinks. For instance, daya according to Sayama meant "upstream" (Zuoshan 2011:1. 16), while to Dakis Pawan it means "upward slope" (13 note 5, 16 note 28$)$. One can imagine Sayama standing there, looking upland, hearing daya and slightly misunderstanding what it referred to, in a scene reminiscent of Quine's thought experiment with gavagai (Quine 2000 [1959]) with an added complication: the passage of nearly a hundred years of time.

12 Thanks to Tsukida Naomi for pointing out the origin of Dàozé.

13 Based on Shen Mingren's account, which I discussed in chapters 3 and 4, the Rainbow Bridge is the alpha and omega of Seediq belief. The spirit river, a Seediq Styx, that flows under the bridge originates in the wellspring of life, which shoots out of the spirit world in the form of a rainbow. The creek beside which Mona Rudo has his colloquy with Hanaoka Ichirō and sings the Song of the Seediq Bale with his father in the film is both downriver from the source and upriver from the destination. The water in the creek represents the flow of life, language, and time, halfway between origin and end.

1 In the scenes in the film set in 1895, 1902, and 1903, warriors light the fuses of their matchlocks by sparking flint, but earlier in the 19th century they had used tinderlock guns, where instead of a match cord, the fire that lights the powder is transmitted through tinder.

2 Thanks to Professor Susan Lin for directing me to evidence that indigenous peoples were making their own black powder in the early 20th century (Lin 2016: 256).

3 Paul Barclay has argued that the Government-General used different methods in the Han Chinese plains and the indigenous mountains, describing the difference in Foucauldian terms: "Colonial rule in Han-dominated Taiwan took on a coloration of nation building in Japan, under a regime of governmentality/discipline, whereas the indigenous territory of Taiwan was ruled under a hybrid regime of punishment and biopol-itics, at least until the 1930s" (Barclay 2017: 32). In the 1930s, the state did try to discipline, to get inside the heads of, the "raw savages," whom they now referred to respectfully as Takasago, in order to turn them into ardent volunteers. To the extent that Foucauldian discipline is a plausible interpretation of postwar society, the Kuomintang tried to discipline the Seediq, too, after 1945.

I myself understand the Seediq encounter with modernity as a process of "domestication," a word from a root meaning "house" that counts domination and domicile among its many cognates. In trying to domesticate the Seediq people, the state has governed and educated them and capital has exploited them, but the Seediq have been trying to self-domesticate, meaning to regain control of their own governance, education, and livelihood in order to create communities where they can feel at home.

To make themselves feel at home, they have to maintain a community/market distinction, where gift exchange is practiced in the community and commodity exchange is reserved for the market. There had long been a place in Seediq culture for commodity exchange by barter or pila payment, and there is still a place for gift exchange. 
4 With more recent technological developments, there are now e-alang on the instant messaging app LINE dedicated to language learning, cultural study, or, ad infinitum, some political candidate or representative's important activities.

5 Despite appearances, "means" and "meaning" are not cognates, but derive from two different Proto-Indo-European roots, according to the Online Etymology Dictionary.

6 In the current legal regime, indigenous peoples are either "plains" or "mountain." The Seediq are "mountain." Individuals are "mountain," according to Article 2 of the Status Act For Indigenous Peoples, if they can prove descent from "permanent residents of the mountain administrative zone before the recovery of Taiwan" in 1945 based on census records compiled by the Japanese. Non-indigenous spouses do not get status, but children born to "mixed" couples do. Maybe eventually, indigenous communities at whatever level will be able to decide who belongs to them, but at present, indigeneity in Taiwan is based on ancestry.

1 Modern values are supposedly "universal," as in the Universal Declaration of Human Rights. However widely the rights apply - "human" would appear to limit their application to a single Earth-bound species - the declaration is a historical document. As products of history, which did not stop in 1948, the rights are amenable to improvement, although they remain foundational: see Article 1 of the United Nations Declaration on the Rights of Indigenous Peoples in 2007.

2 Anthony Pym cites Charles Sanders Peirce for the term semiosis (Pym 2010: 107), but relates Peirce to Roman Jakobson (108). As I explain in endnote 6 to chapter 2 and the conclusion to chapter 7, I understand semiotic processes, including translation, in Jakobsonian terms.

3 In her own translational practice, Gayatri Spivak tries to let the subaltern speak by foreignizing: instead of a domesticating translation like "wet-nurse," Spivak translates the title of Mahasweta Devi's story literally - or almost - into "breast-giver" (Spivak 1987). The title, "স্তন্যদায়িনী" (stan'ya-dāyinī), is "breast" (stan 'ya) "giver" (dāyinī). But there is a bit more to dāyinin than "giver." Dāyinin is a female giver who "shows up in the liturgy for various goddesses," according to Shashwati Talukdar. In Bengali, the title turns the character into a universal mother.

4 Though I have cited works of colonial and postcolonial translation studies by Maria Tymoczko (see ch. 2 note 6 ) and Douglas Robinson (see ch. 6 note 2), I could have done a lot more to compare colonial and postcolonial translators with indigenous translators, the colonial translators who do not have an easy path to political postcoloniality. I hope to do more in an article on the translation of "sovereignty" into Seediq in the context of recent developments in Taiwan with implications for the linguistic, cultural, and political sovereignty of indigenous peoples.

5 Thanks to Louis Jacques-Dorais, a man with a lot of how, and, I am sure, a lot of why, for the analysis of qanuqtuurniq.

6 In response to James Clifford's discussion of the Hawaiian perspective on the past, I would argue that modernity has to have given the Hawaiians a different sense of the past. It has certainly given the Seediq a different sense of the past. The "myth" of the Pusu Qhuni once told Seediq people where they came from, but no Seediq person would take it seriously as history today. Today, Seediq people can make a distinction between mythic and historical narratives, at least between 神話 shénhuà, “myth," and 歷史 lìsh "history." A task for the Seediq now is to translate such distinctions into Seediq. A task I have set myself is the investigation of whether translations into Seediq affect how Seediq speakers understand the original concepts.

Barclay, Paul D. (2005) "Cultural Brokerage and Interethnic Marriage in Colonial Taiwan: Japanese Subalterns and Their Aborigine Wives, 1895-1930," Journal of Asian Studies, 64.2 (May): 323-360.

Barclay, Paul D. (2017) Outcasts of Empire: Japan's Rule on Taiwan's “Savage Border," 1874-1945, Oakland: University of California Press. 
Bawan Danaha (Pawan Tanah; Shen Mingren) (1998) Chongxin Zuling de Minzu: Saideke Ren (The People Who Worship Ancestral Spirits: The Seediq), Taibei: Haiweng.

Berry, Michael (2008) A History of Pain: Trauma in Modern Chinese Literature, New York: Columbia University Press.

Campbell, William (1896) "The Island of Formosa: Its Past and Future," The Scottish Geographical Magazine, 12: facing 398, www.reed.edu/formosa/gallery/Map_pages/ Island_Maps/Campbell2_S.html.

Chiu, Kuei-fen (2017) "Violence and Indigenous Visual History: Interventional Historiography in Seediq Bale and Wushe, Chuanzhong Island," in Kuei-fen Chiu, Ming-yeh T. Rawnsley, and Gary D. Rawnsley (eds), Taiwan Cinema: International Reception and Social Change, New York: Routledge, 146-158.

Deng Xiangyang (2000) Fengzhong Feiying: Wushe Shijian Zhenxiang ji Huagang Chuzi de Gushi (Dana Sakura/Cherry Blossoms in the Wind: The Truth of the Musha Incident and the Story of Hanaoka Hatsuko [Obing Tado]), Taibei: Yushan.

Egawa Hiromichi (1970) Musha no Chizakura (Blood Cherries of Musha), Tōkyō: Morinaga Insatsu.

Guo Mingzheng (Dakis Pawan) (2011) Zhenxiang Balai: Saideke Balai de Lishi Zhenxiang yu Suipai Zhaji (Truth Bale: The Historical Truth of Seediq Bale and a Production Diary), Taibei: Yuanliu.

Guo Mingzheng (Dakis Pawan) (2012) You Jian Zhenxiang: Saidekezu yu Wushe Shijian (Seeing the Truth Again: The Seediq People and the Musha Incident), Taibei: Yuanliu.

Hattori Heijirō (1981 [1931]) "Musha Jiken Nitsuite" (Concerning the Musha Incident), in Tai Kokuki (Dai Guohui) (ed), Taiwan Musha Hōkijiken: Kenkyū to Shiryō (The Uprising at Musha, Taiwan: Research and Materials), Tōkyō: Shakai Shisōsha, 535-561.

Hsiau, A-chin (2000) Contemporary Taiwanese Cultural Nationalism, London and New York: Routledge.

Jian Hongmo, Yiwan Beilin (Iwan Pering), and Guo Mingzheng (Dakis Pawan) (2002) Qingliu Buluo Shengming Shi (Qingliu Village Community Life Histories), Taibei: Yongwang Wenhua.

Kumu Tapas (2004) Ndaan pccbu sediq ka dTanax Tunux cbiyaw (The Story of the Battle by the Seediq with the Red Heads in the Past)/Wushe Shijian Koushu Lishi Gushiji (Collection of Oral History Stories of the Musha Incident).

Lin, Chin-ju (2019) "Exploring the Gendered Cultural Politics of Seediq Bale," Taiwan Insight (February 21), https://taiwaninsight.org/2019/02/21/exploring-the-genderedcultural-politics-of-seediq-bale/.

Liu Zhijun (2016) "Wei Desheng Saideke Balai de Xinggou Mailuo" (The Context of Formation of Wei Te-sheng's Seediq Bale), Taiwan Wenxue Yanjiu Xuebao (Journal of Taiwan Literary Studies), 23 (October): 9-37.

Marx, Karl; Martin Milligan (trans) (2007 [1844]) Economic and Philosophic Manuscripts of 1844, Mineola, NY: Dover.

Qiu Ruolong (2011 [1990]) Manhua Balai: Taiwan di yi bu Wushe Shijian Lishi Manhua (Comic Bale: The First Historical Comic of the Musha Incident), Taibei: Yuanliu.

Simon, Scott (2018) "Penser avec des oiseaux: L'ornithomancie et l'autochtonie à Taïwan," Anthropologie et sociétés, 42.2-3: 151-169.

Simon, Scott and Awi Mona (Chih-Wei Tsai) (2015) "Indigenous Rights and Wildlife Conservation: The Vernacularization of International Law on Taiwan," Taiwan Journal of Human Rights, 3.1 (June): 3-31.

Stainton, Michael (2000) “'Through Love and Suffering': The Role of the Presbyterian Church in Taiwan's Democratization," paper for the Joint Center for Asia-Pacific Studies 
Annual Conference on Democracy and Identity Politics, Toronto, December 4, https:// faculty.washington.edu/stevehar/Love\%20\&\%20Suffering.pdf.

Tengjing Zhijinzhi (Fujii Shizue) (1997) Rizhi Shiqi Taiwan Zongdufu Lifan Zhengce (The Savage Management Policy of the Taiwan Government-General of Taiwan During the Period of Japanese Governance), Taibei: Wenyingtang.

Tsing, Leo T. S. (2001) Becoming Japanese: Colonial Taiwan and the Politics of Identity Formation, Los Angeles: University of California Press.

Veracini, Lorenzo (2012) "Review of 'Warriors of the Rainbow: Seediq Bale', Directed by Wei Te-sheng," in Chris Berry et al. "Reviews," Transnational Cinemas, 3.2: 243-244.

Wei Desheng (Wei Te-sheng) (2000) Saideke Balai (Seediq Bale), Taibei: Xinwenju (Government Information Office).

Wei Desheng (Wei Te-sheng) (2002) Xiao Daoyan Shiye Riji: Huangjinyu Jiang Samuer (Little Director's Diary of Unemployment: The Goldfish General Samuel), Taibei: Shibao wenhua.

Wei Desheng (Wei Te-sheng) (2011) Daoyan Balai: Teyouzhong Wei Desheng de Saideke Balai shouji (Director Bale: Endemic Species/Particularly Spunky Wei Te-sheng's Seediq Bale Diary), Taibei: Yuanliu.

Wu He; Michael Berry (trans) (2017 [1999]) Remains of Life, New York: Columbia University Press.

Xiaoquan Tie (Koizumi Magane); Huang Tingzhuan and He Peiyi (trans) (2014 [1933]) Taiwan Tusu Zhi (Record of Local Taiwan Customs), Taibei: Yuanminhui (Council of Indigenous Peoples).

Yan Yunnong (2011 [2004]) Saideke Balai (Seediq Bale), Taibei: Yuanliu.

Zhongchuan Haoyi and Hegesen Minnan (Nakagawa Kōichi and Wakamori Tamio) (eds) (1992 [1980]) Wushe Shijian Tufa De Dabeiju (Musha Incident: An Unexpected Great Tragedy), Taibei: Wuling.

Zhou Wanyao (2011) "Yingxiong, Yingxiong Chongbai ji qi Fanmingti" (Hero, HeroWorship, and Its Antithesis), in Guo Mingzheng (Dakis Pawan) (ed) Zhenxiang Balai: Saideke Balai de Lishi Zhenxiang yu Suipai Zhaji (Truth Bale: The Historical Truth of Seediq Bale and a Production Diary), Taibei: Yuanliu, 2-8.

Asai, Erin (1953) The Sedik Language of Formosa, Kanazawa, Japan: Cercle Linguistique de Kanazawa, Kanazawa University, 1-84.

Boas, Franz (1911) "Introduction," in Handbook of American Indian Languages, Part 1, Washington, DC: Smithsonian Institution, Bureau of American Ethnology, Bulletin 40.

Covell, Ralph R. (1956) "Sediq Syntax as Related to Problems of Bible Translation," The Bible Translator, 7.4: 171-185.

Cronin, Michael (2003) Translation and Globalization, New York and London: Routledge.

Evans, Nicholas (2010) Dying Words: Endangered Languages and What They Have to Tell Us, Chichester, West Sussex: Wiley-Blackwell.

Guo Mingzheng (Dakis Pawan) (2011) Zhenxiang Balai: Saideke Balai de Lishi Zhenxiang yu Suipai Zhaji (Truth Bale: The Historical Truth of Seediq Bale and a Production Diary), Taibei: Yuanliu.

Holmer, Arthur J. (1995) "Translationese in Seediq," unpublished manuscript.

Holmer, Arthur J. (1996) A Parametric Grammar of Seediq, Lund, Sweden: Lund University Press.

Holmer, Arthur J. (2002) “The Morphology and Syntax of Seediq Focus," in Fay Wouk and Malcom Ross (eds), The History and Typology of Western Austronesian Voice Systems, Canberra, Australia: Pacific Linguistics, 333-354. 
Huang, Shuan-fan, Lily I-wen Su, and Hsiu-hsu Lin (1998) A Functional Reference Grammar of Seediq, Taipei: Graduate Institute of Linguistics, National Taiwan University.

Huang Yijuan and You Wenxing (2011) Dianying Balai: Saideke Balai muqian muhou quan jilu (Movie Bale: Complete Record of Seediq Bale Behind the Scenes and in Front), Taibei: Yuanliu.

Jakobson, Roman and Morris Halle (1971 [1956]) "Two Aspects of Language and Two Types of Aphasic Disturbances," in Fundamentals of Language, 2nd revised edition, Berlin and New York: Mouton de Gruyter, 69-96.

Ogawa Naoyoshi and Asai Erin (1935) Gengo ni Yoru Taiwan Takasago-zoku Densetsu-shū (The Myths and Traditions of the Taiwan Takasago Tribes), Taihoku: Teikoku Daigaku Gengo-gaku Kenkyu-shitsu.

Toury, Gideon (1980) In Search of a Theory of Translation, Tel Aviv: The Porter Institute for Poetics and Semiotics.

Toury, Gideon (1985) "Aspects of Translating into Minority Languages from the Point of View of Translation Studies," Multilingua, 4.1: 3-10.

Tymoczko, Maria (1999) Translation in a Postcolonial Context: Early Irish Literature in English Translation, London and New York: Routledge.

Wei Desheng (Wei Te-sheng) (2011) Daoyan Balai: Teyouzhong Wei Desheng de Saideke Balai shouji (Director Bale: Endemic Species/Particularly Spunky Wei Te-sheng's Seediq Bale Diary), Taibei: Yuanliu.

Anon., Taiwan Zongdufu Jingwuju (Department of Police Affairs, Government-General of Taiwan) (2002 [n.d.]) "Wushe Shijian Zhi" (Record of the Musha Incident), in Dai Guohui (ed); Wei Tingchao (trans), Taiwan Wushe Fengqi Shijian: Yanjiu yu Ziliao (The Uprising at Musha, Taiwan: Research and Materials), Taibei xian, Xindian shi: Guoshiguan (Academia Historica), 475-708.

Bawan Danaha (Pawan Tanah; Shen Mingren) (1998) Chongxin Zuling de Minzu: Saideke Ren (The People Who Worship Ancestral Spirits: The Seediq), Taibei: Haiweng.

Deng Xiangyang (2000) Fengzhong Feiying: Wushe Shijian Zhenxiang ji Huagang Chuzi de Gushi (Dana Sakura/Cherry Blossoms in the Wind: The Truth of the Musha Incident and the Story of Hanaoka Hatsuko [Obing Tado]), Taibei: Yushan.

Guan Wenhui (Kuan Wen-hui) (2016) "Fenghua Zaixian de Beizhuyi - tan Taiyazu Beizhuyi de Lishi he Gongyi zhi Mei" (Return to Glory - A Discussion of the History and the Beauty of the Craftsmanship of Atayal Beaded Shell Clothes), Taiwan Gongyi (Taiwan Crafts), 61 (June): 64-67.

Guo Mingzheng (Dakis Pawan) (2011) Zhenxiang Balai: Saideke Balai de Lishi Zhenxiang yu Suipai Zhaji (Truth Bale: The Historical Truth of Seediq Bale and a Production Diary), Taibei: Yuanliu.

Ninomiya Chikara (ed) (1932) Sēdakka Bangoshu (Seediq Savage Language Compendium), Taichū-shū Keimubu; Taiwan Shinbun-sha.

Ogawa Naoyoshi and Asai Erin (1935) Gengo ni Yoru Taiwan Takasago-zoku Densetsu-shū (The Myths and Traditions of the Taiwan Takasago Tribes), Taihoku: Teikoku Daigaku Gengo-gaku Kenkyu-shitsu.

Qiu Ruolong (2011 [1990]) Manhua Balai: Taiwan di yi bu Wushe Shijian Lishi Manhua (Comic Bale: The First Historical Comic of the Musha Incident), Taibei: Yuanliu.

Wei Desheng (Wei Te-sheng) (2000) Saideke Balai (Seediq Bale), Taibei: Xinwenju (Government Information Office).

Yiwan Beilin (Iwan Pering) (2006) “Utux, Kongjian, Jiyi yu Buluo Jiangou: Yi Alang Tongan yu Alang Sipo wei zhu de Taolun" (Spirits, Space, Memory, and Village Community 
Construction: Discussion Mainly of Tongan and Sipo), Master's thesis, Guoli Donghua Daxue (National Dong Hwa University).

Zeng Ruilin (Temi Nawi) (1994) Saidekezu Shenhua Gushi (Mythic Stories of the Seediq People), Puli, Taiwan: Nantou xian Tianzhujiao Shandi Fuwu Yanjiushe.

Barclay, Paul D. (2017) Outcasts of Empire: Japan's Rule on Taiwan's "Savage Border," 1874-1945, Oakland: University of California Press.

Bawan Danaha (Pawan Tanah; Shen Mingren) (1998) Chongxin Zuling de Minzu: Saideke Ren (The People Who Worship Ancestral Spirits: The Seediq), Taibei: Haiweng.

Deng Xiangyang (1998) Wushe Shijian (Musha Incident), Taibei: Yushan.

Deng Xiangyang (2000) Fengzhong Feiying: Wushe Shijian Zhenxiang ji Huagang Chuzi de Gushi (Dana Sakura/Cherry Blossoms in the Wind: The Truth of the Musha Incident and the Story of Hanaoka Hatsuko [Obing Tado]), Taibei: Yushan.

Jiang Baozhen (2007) "Shengtai zhong bukehuoque zhi huo" (Ecologically Indispensable Fire), Kexueren (The Scientist/Scientific American), 67 (September): 71-73.

Liu Bizhen (Liu Pi-chen) (2011) "Bianxu" (Editorial Introduction), in Zuoshan Rongji (Sayama Yūkichi), Fanzu Diaocha Baogaoshu disice (Savage Races Survey Report vol. 4 [in two parts, one for central Taiwan, one for the east coast]), Nangang, Taibei: Zhongyanyuan (Academia Sinica), iii-viii.

Ohnuki-Tierney, Emiko (2002) Kamikaze, Cherry Blossoms, and Nationalisms: The Militarization of Aesthetics in Japanese History, Chicago: University of Chicago Press.

Qiu Ruolong (2011 [1990]) Manhua Balai: Taiwan di yi bu Wushe Shijian Lishi Manhua (Comic Bale: The First Historical Comic of the Musha Incident), Taibei: Yuanliu.

Sayama Yūkichi (1917) Banzoku Chōsa Hōkokusho daiichibu (Savage Races Survey Report vol. 4 [in two parts, one for central Taiwan, one for the east coast]), Rinji Taiwan Kyūkan Chōsakai.

Simon, Scott (2012) "Politics and Headhunting Among the Formosan Sejiq: Ethnohistorical Perspectives," Oceania, 82: 164-185.

Wei Desheng (Wei Te-sheng) (2000) Saideke Balai (Seediq Bale), Taibei: Xinwenju (Government Information Office).

Zuoshan Rongji (Sayama Yūkichi) (2011 [1917]) Fanzu Diaocha Baogaoshu disice (Savage Races Survey Report vol. 4 [in two parts, one for central Taiwan, one for the east coast]), Nangang, Taibei: Zhongyanyuan (Academia Sinica).

Appiah, Kwame Anthony (2012 [1993]) “Thick Translation," in Lawrence Venuti (ed), The Translation Studies Reader, 3rd edition, New York: Routledge, 331-343.

Aweihebaha (Awi Hepah; Gao Aide); Xu Jielin (ed); Lin Daosheng (trans) (2000 [1985]) Aweihebaha de Wushe Shijian Zhengyan (Awi Hepah Bears Witness to the Musha Incident), Taibei: Taiyuan.

Bawan Danaha (Pawan Tanah; Shen Mingren) (1998) Chongxin Zuling de Minzu: Saideke Ren (The People Who Worship Ancestral Spirits: The Seediq), Taibei: Haiweng.

Deng Xiangyang (2000) Fengzhong Feiying: Wushe Shijian Zhenxiang ji Huagang Chuzi de Gushi (Dana Sakura/Cherry Blossoms in the Wind: The Truth of the Musha Incident and the Story of Hanaoka Hatsuko [Obing Tado]), Taibei: Yushan.

Geertz, Clifford (1973) "Thick Description: Toward an Interpretative Theory of Culture," in The Interpretation of Cultures, New York: Basic Books, 3-30.

Guo Mingzheng (Dakis Pawan) (2011) Zhenxiang Balai: Saideke Balai de Lishi Zhenxiang yu Suipai Zhaji (Truth Bale: The Historical Truth of Seediq Bale and a Production Diary), Taibei: Yuanliu.

Huang Linghua (Iwan Nawi) (2003) "Xu” (Introduction), in Qiu Ruolong; Huang Linghua (Iwan Nawi) (trans), Taiwan Yuanzhumin Lishi Manhuashu Wushe Shijian Saidekezu 
Todayu Banben (Toda Sediq Language Version of the Taiwan Indigenous Historical Comic Book Musha Incident), Taibei: Jiaoyuju (Ministry of Education).

Huang Yijuan and You Wenxing (2011) Dianying Balai: Saideke Balai muqian muhou quan jilu (Movie Bale: Complete Record of Seediq Bale Behind the Scenes and in Front), Taibei: Yuanliu.

Liao Zhaoxiang (2017) "Meixi Buluo Tui Ziran Nongye: Balai Zhu Dengchang” (Meixi Village Promotion of Natural Agriculture: The Debut of the True Pig), Zhongguo Shibao (China Times) (June 17).

Masaw, Mona (Liao Shouchen) (1998) Taiyazu de Shehui Zuzhi (Atayal Social Organization), Hualian: Sili Ciji Yixue Ji Renwen Shehui Xueyuan (Tzu Chi University Research Center on Aboriginal Health).

Pacidal, Nakao Eki (2012) "Zhongjianzhe zhi Lian: Saideke Balai de Yuanzhumin Lishi Yanjiuzhe Yingxiang" (The Face of the Inbetweener: The Image of [the] Indigenous History Researcher as Reflected in Seediq Bale), Taida wenshizhe xuebao (Humanitas Taiwanica), 77 (November): 167-197.

Pihuwarisu (Pihu Walis; Gao Yongqing) (1988) Musha Hizakuara no Kuruizaki: Gyakusatsu Jiken Ikinokori no Shogen (The Madness of the Cherry Blossoms of Musha: Testimony of Survival of an Incident of Massacre), Tōkyō: Kyōbunkan.

Simon, Scott (2012a) "Politics and Headhunting Among the Formosan Sejiq: Ethnohistorical Perspectives," Oceania, 82: 164-185.

Simon, Scott (2012b) Sadyaq Balae! L'Autochtonie Formosane Dans Tous Ses États (Seediq Bale! Formosan Indigeneity in All Its States), Ottawa, Canada: University of Ottawa Press.

Simon, Scott (2015) "Real People, Real Dogs, and Pigs for the Ancestors: The Moral Universe of 'Domestication' in Indigenous Taiwan," American Anthropologist, 117.4: 693-709.

Simon, Scott and Awi Mona (Chih-Wei Tsai) (2015) "Indigenous Rights and Wildlife Conservation: The Vernacularization of International Law on Taiwan," Taiwan Journal of Human Rights, 3.1: (June) 3-31.

Wang Meixia (Wang Mei-hsia) (2003) "Cong Gaga de Duoyixing Kan Taiyazu de Shehui Xingzhi” (Exploring the Social Characteristics of the Dayan: Multiple Meanings of Gaga), Taiwan Renlei Xuekan (Taiwan Journal of Anthropology), 1.1: 77-104.

Wang, Mei-hsia (2008) "The Reinvention of Ethnicity and Culture: A Comparative Study on the Atayal and the Truku in Taiwan," Journal of Archaeology and Anthropology, 68: $1-44$.

Wang Meixia (Wang Mei-hsia) and Yiwan Beilin (Iwan Pering) (2012) “"Wenhua Dongqilai': Saidekezu Wenhua Chanye de Yanjiu” (Activating the Sediq Culture: A Study of Cultural Industry in a Sediq Community), Minsu Quyi (Journal of Chinese Ritual, Theater and Folklore), 176 (June): 1-53.

Wei Desheng (Wei Te-sheng) (2000) Saideke Balai (Seediq Bale), Taibei: Xinwenju (Government Information Office).

Wei Desheng (Wei Te-sheng); Yiwan Nawei (Iwan Nawi) (trans) (2014) Kari Toda Patas eyga Sediq balay (The Toda Language Screenplay for Seediq Bale)/Saideke Balai Saidekeyu Jubenshu (Seediq-Language Screenplay for Seediq Bale), Taibei: Yushan.

Xiaoquan Tie (Koizumi Magane); Huang Tingzhuan and He Peiyi (trans) (2014 [1933]) Taiwan Tusu Zhi (Record of Local Taiwan Customs), Taibei: Yuanminhui (Council of Indigenous Peoples).

Yan Yunnong (2011 [2004]) Saideke Balai (Seediq Bale), Taibei: Yuanliu. 
Yiwan Nawei (Iwan Nawi) (2014) "Fanyi Balai" (True Translation)/“Kari Sediq Balay" (True Seediq Language), in Wei Desheng (Wei Te-sheng); Yiwan Nawei (Iwan Nawi) (trans), Kari Toda Patas eyga Sediq balay (The Toda Language Screenplay for Seediq Bale)/Saideke Balai Saidekeyu Jubenshu (Seediq-Language Screenplay for Seediq Bale), Taibei: Yushan, 13-17.

Zuoshan Rongji (Sayama Yūkichi) (2011 [1917]) Fanzu Diaocha Baogaoshu disice (Savage Races Survey Report vol. 4 [in two parts, one for central Taiwan, one for the east coast]), Nangang, Taibei: Zhongyanyuan (Academia Sinica).

Barclay, Paul D. (2017) Outcasts of Empire: Japan's Rule on Taiwan's "Savage Border," 1874-1945, Oakland: University of California Press.

Bawan Danaha (Pawan Tanah; Shen Mingren) (1998) Chongxin Zuling de Minzu: Saideke Ren (The People Who Worship Ancestral Spirits: The Seediq), Taibei: Haiweng.

Berry, Michael (2008) A History of Pain: Trauma in Modern Chinese Literature, New York: Columbia University Press.

Bhabha, Homi K. (1994) The Location of Culture, New York and London: Routledge.

Deloria, Phillip J. (2006) "What Is the Middle Ground, Anyway?" The William and Mary Quarterly, Third Series, 63.1 (January): 15-22.

Deng Xiangyang (2000) Fengzhong Feiying: Wushe Shijian Zhenxiang ji Huagang Chuzi de Gushi (Dana Sakura/Cherry Blossoms in the Wind: The Truth of the Musha Incident and the Story of Hanaoka Hatsuko [Obing Tado]), Taibei: Yushan.

Fox, James J. (2005). "Ritual Languages, Special Registers and Speech Decorum in Austronesian Languages," in Alexander Adelaar and Nikolaus P. Himmelmann (eds), The Austronesian Languages of Asia and Madagascar, London and New York: Routledge, 87-109.

Guo Mingzheng (Dakis Pawan) (2011) Zhenxiang Balai: Saideke Balai de Lishi Zhenxiang yu Suipai Zhaji (Truth Bale: The Historical Truth of Seediq Bale and a Production Diary), Taibei: Yuanliu.

Hirano, Katsuya, Lorenzo Veracini, and Toulouse-Antonin Roy (2018) "Vanishing Natives and Taiwan's Settler-Colonial Unconsciousness," Critical Asian Studies, 50.2: 1-23.

Jian Hongmo, Yiwan Beilin (Iwan Pering), and Guo Mingzheng (Dakis Pawan) (2002) Qingliu Buluo Shengming Shi (Qingliu Village Community Life Histories), Taipei: Yongwang Wenhua.

Li Yiqian (Lee Yi-chien) (2016) "Duochong Xunhua yu Yuhui Zhengming: Saideke Balai Zimu Fanyi zhong de Yiyi Liuzhuan" (Multiple Domestications and Indirect Rectification: Semiotic Shifts in the Subtitle Translation of Seediq Bale), Taiwan Wenxue Yanjiu Xuebao (Journal of Taiwan Literary Research), 23: 39-68.

Morgan, Lewis Henry (1871) Systems of Consanguinity and Affinity of the Human Family, Smithsonian Contributions to Knowledge, Washington, DC: Smithsonian Institution.

Mori Ushinosuke (1917) Taiwan Banzokushi (Record of the Savage Tribes of Taiwan), Taihoku, Taipei: Rinji Taiwan Kyūkan Chōsakai.

Niranjana, Tejaswini (1992) Siting Translation: History, Post-structuralism, and the Colonial Context, Berkeley and Los Angeles: University of California Press.

Pym, Anthony (2014 [2010]) Exploring Translation Theories, 2nd edition, New York and London: Routledge.

Qiu Ruolong (2011 [1990]) Manhua Balai: Taiwan di yi bu Wushe Shijian Lishi Manhua (Comic Bale: The First Historical Comic of the Musha Incident), Taibei: Yuanliu. 
Quine, Willard V. O. (2000 [1959]) "Meaning and Translation," in Lawrence Venuti (ed), The Translation Studies Reader, 1st edition, London and New York: Routledge, 94-112.

Rafael, Vicente L. (1988) Contracting Colonialism: Translation and Christian Conversion in Tagalog Society Under Early Spanish Rule, Durham, NC: Duke University Press.

Robinson, Douglas (1997) Translation and Empire: Postcolonial Theories Explained, London and New York: Routledge.

Rosman, Abraham and Paula G. Rubel (2003) “Are Kinship Terminologies Translatable?" in Paula G. Rubel and Abraham Rosman (eds), Translating Cultures: Perspectives on Translation and Anthropology, Oxford and New York: Berg Publishers, 269-283.

Simon, Scott (2018) "Penser avec des oiseaux: L'ornithomancie et l'autochtonie à Taïwan," Anthropologie et sociétés, 42.2-3: 151-169.

Sterk, Darryl (2017) "Mona Rudo's Scar: Two Kinds of Epic Identity in Seediq Bale," in Chiu Kuei-fen, Ming-yeh T. Rawnsley, and Gary D. Rawnsley (eds), Taiwan Cinema: International Reception and Social Change, London and New York: Routledge, 173-189.

Tiemi'naweiyi (Temi Nawi) (2000) Atayal Weaving Culture, bilingual edition, Self-Published.

Tiemi'naweiyi (Temi Nawi) (2009) Kari Pnsltudan Rudan (Stories Passed Down by the Elders)/Saidekezu Koushu Chuantong Wenhua Gushi (Traditional Oral Cultural Stories of the Seediq People), 2 volumes, Nantou: Guojia tushuguan.

Wei Desheng (Wei Te-sheng) (2000) Saideke Balai (Seediq Bale), Taibei: Xinwenju (Government Information Office).

White, Richard (1991) The Middle Ground: Indians, Empires, and Republics Great Lakes Region, 1650-1815, Cambridge: Cambridge University Press.

Xiaoquan Tie (Koizumi Magane); Huang Renhui (trans) (2014 [1932]) Fanxiang Fengwu Ji (Notes of Scenes in Savage Territory), Taibei: Yuanminhui (Council of Indigenous Peoples).

Xiaoquan Tie (Koizumi Magane); Huang Tingzhuan and He Peiyi (trans) (2014 [1933]) Taiwan Tusu Zhi (Record of Local Taiwan Customs), Taibei: Yuanminhui (Council of Indigenous Peoples).

Yiwan Nawei (Iwan Nawi) (2014) "Fanyi Balai" (True Translation)/“Kari Sediq Balay" (True Seediq Language), in Wei Desheng (Wei Te-sheng); Yiwan Nawei (Iwan Nawi) (trans) Kari Toda Patas eyga Sediq balay (The Toda Language Screenplay for Seediq Bale)/Saideke Balai Saidekeyu Jubenshu (Seediq-Language Screenplay for Seediq Bale), Taibei: Yushan, 13-17.

Zeng Ruilin (Temi Nawi) (1994) Saidekezu Shenhua Gushi (Mythic Stories of the Seediq People), Puli, Taiwan: Nantou xian Tianzhujiao Shandi Fuwu Yanjiushe.

Zhou Wanyao (2011) "Yingxiong, Yingxiong Chongbai ji qi Fanmingti" (Hero, HeroWorship, and Its Antithesis), in Guo Mingzheng (Dakis Pawan) (ed) Zhenxiang Balai: Saideke Balai de Lishi Zhenxiang yu Suipai Zhaji (Truth Bale: The Historical Truth of Seediq Bale and a Production Diary), Taibei: Yuanliu, 2-8.

Zuoshan Rongji (Sayama Yūkichi) (2011 [1917]) Fanzu Diaocha Baogaoshu disice (Savage Races Survey Report vol. 4 [in two parts, one for central Taiwan, one for the east coast]), Nangang, Taibei: Zhongyanyuan (Academia Sinica).

Barclay, Paul D. (2017) Outcasts of Empire: Japan's Rule on Taiwan's “Savage Border," 1874-1945, Oakland: University of California Press.

Bawan Danaha (Pawan Tanah; Shen Mingren) (1998) Chongxin Zuling de Minzu: Saideke Ren (The People Who Worship Ancestral Spirits: The Seediq), Taibei: Haiweng. 
Cronin, Michael (2003) Translation and Globalization, New York and London: Routledge. Guo Mingzheng (Dakis Pawan) (2011) Zhenxiang Balai: Saideke Balai de Lishi Zhenxiang yu Suipai Zhaji (Truth Bale: The Historical Truth of Seediq Bale and a Production Diary), Taibei: Yuanliu.

Lin, Pei-hsi (Susan) (2016) "Firearms, Technology and Culture: Resistance of Taiwanese Indigenes to Chinese, European and Japanese Encroachment in a Global Context Circa 1860-1914," dissertation, Nottingham Trent University.

Mühleder, Peter (2013) "The Japanese School Sports Day: The Socio-Cultural Role of a Ritualistic School Event in Contemporary Japan," Vienna Journal of East Asian Studies, 4: 67-96.

Pergnier, Maurice (1989) Les anglicismes: danger ou enrichissement pour la langue française (Anglicisms: Danger or Enrichment for French), Paris: Presses Universitaires de France.

Qiu Ruolong (2011 [1990]) Manhua Balai: Taiwan di yi bu Wushe Shijian Lishi Manhua (Comic Bale: The First Historical Comic of the Musha Incident), Taibei: Yuanliu.

Qiu Ruolong; Huang Linghua (Iwan Nawi) (trans) (2003) Taiwan Yuanzhumin Lishi Manhuashu Wushe Shijian Saidekezu Todayu Banben (Toda Sediq Language Version of the Taiwan Indigenous Historical Comic Book Musha Incident), Taibei: Jiaoyuju (Ministry of Education).

Wei Desheng (Wei Te-sheng) (2000) Saideke Balai (Seediq Bale), Taibei: Xinwenju (Government Information Office).

Wei Desheng (Wei Te-sheng); Yiwan Nawei (Iwan Nawi) (trans) (2014) Kari Toda Patas eyga Sediq balay (The Toda Language Screenplay for Seediq Bale)/Saideke Balai Saidekeyu Jubenshu (Seediq-Language Screenplay for Seediq Bale), Taibei: Yushan.

Wolf, Eric R. (1982) Europe and the People Without History, Berkeley and Los Angeles: University of California Press.

Yan Yunnong (2011 [2004]) Saideke Balai (Seediq Bale), Taibei: Yuanliu.

Zuoshan Rongji (Sayama Yūkichi) (2011 [1917]) Fanzu Diaocha Baogaoshu disice (Savage Races Survey Report vol. 4 [in two parts, one for central Taiwan, one for the east coast]), Nangang, Taibei: Zhongyanyuan (Academia Sinica).

Asad, Talal (1986) "The Concept of Cultural Translation in British Social Anthropology," in James Clifford and George E. Marcus (eds), Writing Culture: The Poetics and Politics of Ethnography, Berkeley and Los Angeles: University of California Press, 141-164.

Boas, Franz (1940 [1896]) "The Limitations of the Comparative Method of Anthropology," in Franz Boas (ed), Race, Language and Culture, New York: The Free Press, 270-280.

Branchadell, Albert (2011) "Minority Languages and Translation," in Yves Gambier and Luc van Doorslaer (eds), Handbook of Translation Studies, v. 2, Amsterdam and Philadelphia: Benjamins, 97-101.

Branchadell, Albert and Lovell Margaret West (eds) (2005) Less Translated Languages, Amsterdam and Philadelphia: Benjamins.

Buden, Boris, Stefan Nowotny, Sherry Simon, Ashok Bery, and Michael Cronin (2009) "Cultural Translation: An Introduction to the Problem, and Responses," Translation Studies, 2.2: 196-219.

Clifford, James (2013) Returns: Becoming Indigenous in the Twenty-First Century, Cambridge: Harvard University Press.

Cronin, Michael (1995) “Altered States: Translation and Minority Languages," TTR: Traduction, Terminologie, Redaction, 8.1: 85-103.

Cronin, Michael (2003) Translation and Globalization, New York and London: Routledge. 
Cronin, Michael (2017) Eco-Translation, New York and London: Routledge.

Crystal, David (2000) Language Death, Cambridge, UK: Cambridge University Press.

Evans, Nicholas (2010) Dying Words: Endangered Languages and What They Have to Tell Us, Chichester, West Sussex: Wiley-Blackwell.

Folaron, Debbie (2015a) "Introduction: Translation and Minority, Lesser-Used and LesserTranslated Languages and Cultures," The Journal of Specialised Translation, 24 (July): $16-27$.

Folaron, Debbie (2015b) "Debbie Folaron Discusses the Role of Language and Translation in Endangered Aboriginal Communities (Cree, Naskapi, Innu) with Julie Brittain and Marguerite MacKenzie," The Journal of Specialised Translation, 24 (July): 2-15.

Grenoble, Lindsay A. and Lenore J. Whaley (2006) Saving Languages: An Introduction to Language Revitalization, Cambridge: Cambridge University Press.

Hacker, Helen Mayer (1951) "Women as a Minority Group," Social Forces, 30.1 (October): 60-69.

Hessell, Nikki (2018) Romantic Literature and the Colonised World: Lessons from Indigenous Translations, Cham, Switzerland: Palgrave Macmillan.

Humboldt, Wilhelm von; Michael Losonsky (ed); Peter Heath (trans) (1989 [1836]) On Language: On the Diversity of Human Language Construction and Its Influence on the Mental Development of the Human Species, Cambridge: Cambridge University Press.

Joseph, John Earl (1987) Eloquence and Power: The Rise of Language Standards and Standard Languages, London: Frances Pinter.

Kame'eleihiwa, Lilikalā (1992) Native Land and Foreign Desires: Pehea Lā E Pono Ai (How Shall We Live in Harmony), Honolulu: Bishop Museum Press.

Koskinen, Kaisa and Päivi Kuusi (2017) "Translator Training for Language Activists: Agency and Empowerment of Minority Language Translators," trans-kom: Journal of Translation and Technical Communication Research, 10.2: 188-213.

Krauss, Michael (1992) "The World's Languages in Crisis," Language, 68.1: 4-10.

Kuusi, Päivi, Leena Kolehmainen, and Helka Riionheimo (2017) "Introduction: Multiple Roles of Translation in the Context of Minority Languages and Revitalisation," transkom: Journal of Translation and Technical Communication Research, 10.2: 138-163.

Larsen, Tord (1987) “Action, Morality, and Cultural Translation," Journal of Anthropological Research, 43.1 (June): 1-28.

Leavitt, John (2011) Linguistic Relativities: Language Diversity and Modern Thought, Cambridge: Cambridge University Press.

Maitland, Sara (2017) What Is Cultural Translation? London and New York: Bloomsbury.

NeSmith, Keao (2017) "Nonsense Prose Neologisms: A Look at Universal Approaches from Polynesian and British Points of View," conference paper for Australex.

Nettle, Daniel and Suzanne Romaine (2000) Vanishing Voices: The Extinction of the World's Languages, Oxford: Oxford University Press.

Ong, Walter J. (2002 [1982]) Orality and Literacy: The Technologization of the Word, New York and London: Routledge.

Pasch, Timothy (2015) "Towards the Enhancement of Arctic Digital Industries: 'Translating' Cultural Content to New Media Platforms," The Journal of Specialised Translation, 24 (July): 187-213.

Pullum, Geoffrey K. (1989) “The Great Eskimo Vocabulary Hoax," Natural Language and Linguistic Theory, 7: 275-281.

Pym, Anthony (2014 [2010]) Exploring Translation Theories, 2nd edition, New York and London: Routledge. 
Simon, Scott (2018) "Penser avec des oiseaux: L'ornithomancie et l'autochtonie à Taïwan," Anthropologie et sociétés, 42.2-3: 151-169.

Spivak, Gayatri Chakravorty (1987) "Breast-Giver," in In Other Words: Essays in Cultural Politics, New York and London: Methuen, 222-240.

Sterk, Darryl (2020) "Ecologizing Seediq: Towards an Ecology of an Endangered Indigenous Language from Taiwan," International Journal of Taiwan Studies, forthcoming.

Sturge, Kate (2007) Representing Others: Translation, Ethnography and the Museum, Manchester: St. Jerome.

Thomason, Sarah A. (2006) "Language Change and Language Contact," in Keith Brown (ed), Encyclopedia of Language and Linguistics, v. 6, Oxford: Elsevier, 339-346.

Thomason, Sarah A. (2007) "Language Contact and Deliberate Change," Journal of Language Contact, 1: 41-62.

Wang Meixia (Wang Mei-hsia) (2014) “Cong Waya kan ziben zhuyi de zhuanhua guocheng: yige Saideke buluo de jingji bianqian" (Exploring the Transformation of Capitalism from Perspectives of Waya: Economic Changes in a Sediq Community), Kaogu renlei xuekan (Journal of Archaeology and Anthropology), 80: 53-102.

Wei Desheng (Wei Te-sheng) (2000) Saideke Balai (Seediq Bale), Taibei: Xinwenju (Government Information Office).

Whorf, Benjamin Lee (1940) "Science and Linguistics," Technology Review (MIT), 42.6 (April): 229-231, 247-248. 